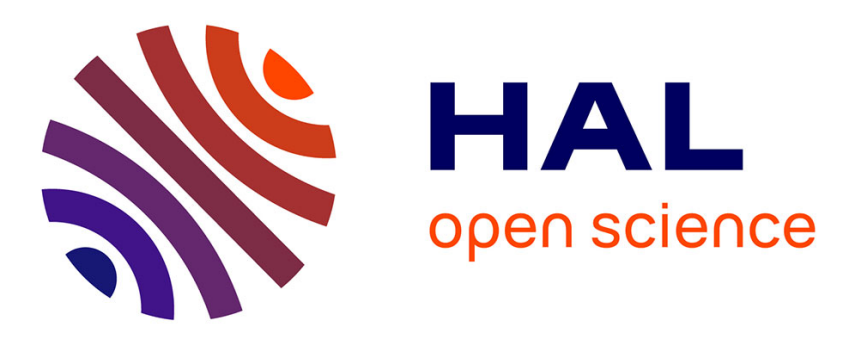

\title{
Superior explicit memory despite severe developmental amnesia: In-depth case study and neural correlates
}

Pierre-Yves Jonin, Gabriel Besson, Renaud La Joie, Jérémie Pariente, Serge Belliard, Christian Barillot, Emmanuel J. Barbeau

\section{To cite this version:}

Pierre-Yves Jonin, Gabriel Besson, Renaud La Joie, Jérémie Pariente, Serge Belliard, et al.. Superior explicit memory despite severe developmental amnesia: In-depth case study and neural correlates. Hippocampus, 2018, 28 (12), pp.867-885. 10.1002/hipo.23010 . inserm-01916086v4

\section{HAL Id: inserm-01916086 https://www.hal.inserm.fr/inserm-01916086v4}

Submitted on 19 Nov 2018

HAL is a multi-disciplinary open access archive for the deposit and dissemination of scientific research documents, whether they are published or not. The documents may come from teaching and research institutions in France or abroad, or from public or private research centers.
L'archive ouverte pluridisciplinaire HAL, est destinée au dépôt et à la diffusion de documents scientifiques de niveau recherche, publiés ou non, émanant des établissements d'enseignement et de recherche français ou étrangers, des laboratoires publics ou privés. 


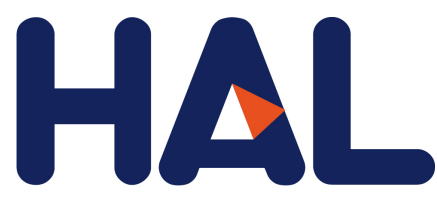

archives-ouvertes

\section{Superior explicit memory despite severe developmental amnesia: In-depth case study and neural correlates}

Pierre-Yves Jonin, Gabriel Besson, Renaud La Joie, Jérémie Pariente, Serge Belliard, Christian Barillot, Emmanuel Barbeau

\section{To cite this version:}

Pierre-Yves Jonin, Gabriel Besson, Renaud La Joie, Jérémie Pariente, Serge Belliard, et al.. Superior explicit memory despite severe developmental amnesia: In-depth case study and neural correlates. Hippocampus, Wiley, 2018, Epub ahead of print. $<10.1002 /$ hipo.23010 $>$. <inserm-01916086v4 $>$

\section{HAL Id: inserm-01916086 http://www.hal.inserm.fr/inserm-01916086v4}

Submitted on 19 Nov 2018

HAL is a multi-disciplinary open access archive for the deposit and dissemination of scientific research documents, whether they are published or not. The documents may come from teaching and research institutions in France or abroad, or from public or private research centers.
L'archive ouverte pluridisciplinaire HAL, est destinée au dépôt et à la diffusion de documents scientifiques de niveau recherche, publiés ou non, émanant des établissements d'enseignement et de recherche français ou étrangers, des laboratoires publics ou privés. 


\title{
Superior explicit memory despite severe developmental amnesia: in-depth case study and neural correlates
}

\author{
Pierre-Yves JONIN(1,2,3, ${ }^{*}$, Gabriel BESSON(1), Renaud LAJOIE(4), Jérémie PARIENTE(5), \\ Serge BELLIARD(3,4), Christian BARILLOT(2) and Emmanuel J. BARBEAU(1) \\ ${ }^{1}$ Brain and Cognition Research Center, CNRS UMR 5549, University of Toulouse Paul Sabatier, Toulouse, \\ France \\ ${ }^{2}$ INRIA, VisAGeS Project Team, CNRS, IRISA, UMR 6074, University of Rennes 1, Rennes, France \\ ${ }^{3}$ Neurology Department, Pontchaillou University Hospital, Rennes, France \\ 4 “Neuropsychology and Imaging of Human Memory” research unit, Normandy University-PSL Research \\ University-INSERM U1077, Caen University Hospital, Caen, France \\ ${ }^{5}$ Toulouse Neuroimaging Center, INSERM U1214, University of Toulouse Paul Sabatier, Toulouse, France
}

Abbreviated title: The extended hippocampal system and context-free memory

Number of text pages: 48

Number of figures: 6

Number of tables: 6

${ }^{*}$ Corresponding author

Pierre-Yves JONIN, Brain and Cognition Research Center, CNRS UMR 5549, University of Toulouse Paul Sabatier, Toulouse, France, +33 619320 708, pierreyves.jonin@chu-rennes.fr

Keywords: amnesia; single case study; new learning; recognition memory; RRID: SCR_009567 


\begin{abstract}
The acquisition of new semantic memories is sometimes preserved in patients with hippocampal amnesia. Robust evidence for this comes from case reports of developmental amnesia suggesting that low-to-normal levels of semantic knowledge can be achieved despite compromised episodic learning. However, it is unclear whether this relative preservation of semantic memory results from normal acquisition and retrieval or from residual episodic memory, combined with effortful repetition. Furthermore, lesion studies have mainly focused on the hippocampus itself, and have seldom reported the state of structures in the extended hippocampal system. Preserved components of this system may therefore mediate residual episodic abilities, contributing to the apparent semantic preservation. We report an in-depth study of Patient KA, a 27-yearold man who had severe hypoxia at birth, in which we carefully explored his residual episodic learning abilities. We used novel speeded recognition paradigms to assess whether KA could explicitly acquire and retrieve new context-free memories. Despite a pattern of very severe amnesia, with a 44-point discrepancy between his intelligence and memory quotients, KA exhibited normal-to-superior levels of knowledge, even under strict time constraints. He also exhibited normal-to-superior recognition memory for new material, again under strict time constraints. Multimodal neuroimaging revealed an unusual pattern of selective atrophy within each component of the extended hippocampal system, contrasting with the preservation of anterior subhippocampal cortices. A cortical thickness analysis yielded a pattern of thinner but also thicker regional cortices, pointing toward specific temporal lobe reorganization following early injury. We thus report the first case of superior explicit learning and memory in a severe case of amnesia, raising important questions about how such knowledge can be acquired.
\end{abstract}




\section{Introduction}

The formation of long-term declarative memories relies on medial temporal lobe (MTL) structures that include the hippocampus and entorhinal, perirhinal and parahippocampal cortices. Many studies have demonstrated that the retrieval of facts or general knowledge acquired before the onset of amnesia can be preserved. For example, Patient HM performed normally when asked to retrieve lexical knowledge acquired before the onset of amnesia, across a wide variety of tasks (Kensinger et al., 2001). However, the question of whether amnesic patients can acquire new knowledge still remains debated.

Patients EP and GP, who both had extensive damage to the whole MTL, were unable to recall or recognize information about famous people or events from the post-onset period (Bayley and Squire, 2005). In the case of Patient EP, intensive repetition of stimuli across 24 learning sessions (controls only required two sessions) failed to yield any evidence of new learning. Even when damage was limited to the hippocampal formation, five other patients performed at chance level when asked to make living/deceased judgments on famous names (Manns et al., 2003). When new explicit learning is observed in amnesia, this learning is usually described as being 1) slower than in controls, 2) achieved through extensive, repeated exposure to the to-be-learned material (Stark et al., 2005), and 3) the result of dedicated learning techniques such as vanishing cues or errorless learning. These features of new knowledge acquisition in amnesia have led some authors to suggest that this kind of learning cannot be considered as declarative, as it relies upon perceptual learning processes (Bayley and Squire, 2002).

Even so, some researchers have found that patients with adult-onset amnesia can acquire a certain amount of new factual knowledge (e.g., Tulving et al., 1991; Van der 
Linden et al., 1996; Kitchener et al., 1998; Verfaellie et al., 2000; Westmacott and Moscovitch, 2001; O’Kane et al., 2004; Stark et al., 2005). More robust evidence for this acquisition has come from patients with developmental amnesia (DA). These patients (e.g., Vargha-Khadem et al., 1997; Brizzolara et al., 2003; Martins et al., 2006; Gardiner et al., 2008; Bindschaedler et al., 2011; Picard et al., 2013; D'Angelo et al., 2015) consistently exhibit low-to-normal levels of knowledge acquisition. They usually have hippocampal atrophy but relatively preserved subhippocampal structures, leading to the suggestion that these structures support the acquisition of new context-free knowledge, such as vocabulary, concepts, semantic facts, and familiarity (i.e., whether stimuli have previously been encountered) (Mishkin et al., 1998). However, interpreting these findings as evidence for preserved semantic learning must be undertaken cautiously, for three main reasons.

First, the conclusion of preserved semantic learning is usually based on the results of tests measuring academic achievement or general knowledge, such as the Information, Vocabulary and Comprehension subtests of the Wechsler Adult Intelligence Scale (WAIS; Vargha-Khadem et al., 1997; Gadian et al., 2001; Brizzolara et al., 2003; Vargha-Khadem et al., 2003; Martins et al., 2006; Bindschaedler et al., 2011; Rosenbaum et al., 2011; Picard et al., 2013; D'Angelo et al., 2016). It should be noted that more thorough assessments of semantic knowledge always elicit performances in the low-to-normal range (Brizzolara et al., 2003; Martins et al., 2006; Bindschaedler et al., 2011) or, in some cases, impaired performances (e.g., Patient KF, Martins et al., 2006; Patient CL, Vicari et al., 2007; Patient Jocelyn, Picard et al., 2013). However, just because some patients with DA perform the Vocabulary or Information subtest of the WAIS correctly does not mean that they have normal semantic memory. Recent findings suggest that their semantic knowledge structure differs from that of healthy individuals (D'Angelo et al., 2016; 
Patient HC, Blumenthal et al., 2017). There is also the question of whether these patients acquire new semantic knowledge in a similar way to healthy individuals, with available evidence suggesting that they do so at a slower pace (e.g., Martins et al., 2006; Gardiner et al., 2008). Furthermore, it is unclear at present whether patients with DA use semantic knowledge as quickly and efficiently as controls. Time constraints need to be used at retrieval to assess this point properly, but to our knowledge this has yet to be done.

Second, a careful examination of published cases of adult-onset amnesia or DA suggests that some patients exhibit residual episodic learning abilities (e.g., VarghaKhadem et al., 1997; Verfaellie et al., 2000; Brizzolara et al., 2003; Martins et al., 2006; Bindschaedler et al., 2011; Picard et al., 2013; D’Angelo et al., 2015). For example, Patient PS, whose damage was thought to be limited to the hippocampal formation (Verfaellie et al., 2000), achieved a general memory index of 90 (Wechsler Memory Scale-Revised; WMS-R), clearly denoting considerable residual abilities for episodic learning. In such cases, apparently preserved semantic learning may very well be the result of these residual episodic learning abilities, albeit requiring more time and effort than in controls (Squire and Zola, 1998).

Third, lesion studies have mostly focused on distinguishing between patients with damage limited to the hippocampal formation or else spread across the whole MTL. However, episodic learning is thought to depend on the so-called extended hippocampal system, which includes the hippocampus, fornix, mammillary bodies, mammillothalamic tract, anterior thalamic nuclei, and retrosplenial cortex (Aggleton et al, 2010). Damage to any part of this system has been shown to result in anterograde amnesia, with contextrich memories being particularly vulnerable (Aggleton and Saunders, 1997; Vann and Nelson, 2015). Accordingly, a detailed investigation of each component of the extended 
hippocampal system is crucial if we are to draw any further inferences about the cognitive profiles of patients with amnesia. Interestingly, in DA, recent evidence has confirmed that damage is not limited to the hippocampal formation. Despite early evidence of abnormalities in the putamen, brainstem, thalamus, and/or retrosplenial cortex (Gadian et al., 2000; Vargha-Khadem et al., 2003), diencephalic abnormalities have only been reported comparatively recently (Bindschaedler et al., 2011; Rosenbaum et al., 2011; Olsen et al., 2013; Rosenbaum et al., 2014). A group study has just confirmed that mammillary body atrophy is quite common (Dzieciol et al., 2017), as is anterior thalamus atrophy. We now have substantial evidence suggesting that some parts of the so-called extended hippocampal system can be affected in DA. Thus, in case reports where damage is restricted to the hippocampal formation, we cannot rule out the possibility of residual explicit learning abilities, owing to the functional preservation of intact components of the extended hippocampal system.

Taken together, evidence of normal knowledge acquisition (i.e., as fast and as efficient as in controls) in amnesia is therefore still lacking. This needs to be demonstrated in cases of severe amnesia with extensive damage to the extended hippocampal system and no residual episodic ability. Here, we describe the case of a new patient with DA who displayed several novel and outstanding features. This patient had the extremely rare condition of selective damage to the whole of the extended hippocampal system. He was severely amnesic, with close to zero residual episodic ability, but displayed superior (i.e. significantly better than controls) abilities on many semantic memory tasks. Experiments involving speeded recognition memory paradigms yielded evidence that he could retrieve and acquire new knowledge as efficiently as controls. We also performed-for the first time in DA to our knowledge a cortical thickness analysis that revealed a pattern of thicker subhippocampal cortex, indicative of profound 
reorganization. This case study suggests that in some instances, and in conditions that remain to be fully elucidated, novel knowledge can be acquired up to a very good level in severe amnesia.

\section{Case description}

KA is a right-handed male who was 27 years old at first testing, when he was referred to our memory clinic for persistent memory issues he and his family had had to face since he was a child. His only notable antecedent was severe neonatal hypoxia. KA was delivered prematurely at 32 weeks of gestation. He suffered from cardiac arrest and hypoxia at birth, requiring intubation and ventilation and a 40-day stay in the intensive neonatal care unit. His development thereafter was unremarkable, and his parents even reported precocious knowledge of the alphabet at age 3, with a normal acquisition rate for language and motor abilities. We did not find any medical history in KA's family, his parents and his brother being free of any specific medical condition. All completed at least 12 years of education and reported normal socio-occupational integration.

However, very early on in his development, his parents also reported a series of everyday situations where KA obviously exhibited marked anterograde amnesia. When asked to perform two simple things, KA always forgot one, and at age 4 years, his teachers worried about his inability to complete the activities he was instructed to perform. By age 7 years, KA's learning disabilities had become a serious concern at school. Despite many consultations in different clinical settings, no clear diagnosis emerged. These difficulties persisted throughout secondary school, leading KA to repeat his first year, then to go to a vocational school where he failed to obtain his vocational diploma despite two attempts. In 2009, his mother heard about memory clinics, which is when KA was referred to us. KA is currently unemployed. He cannot live fully 
independently without the supervision of his parents for administrative tasks, but he can drive, orient himself in very familiar surroundings, and generally take care of himself. KA systematically records most events or thoughts in a notebook he always keeps with him, together with at least three pencils, just in case. In this notebook, he can write ideas shared in conversations he has just had, as well as the place where he left his sunglasses, or something he should think about the next day. Nonetheless, KA is known by his close relations to have an impressive amount of general knowledge.

\section{Neuropsychological background}

\subsection{General cognitive assessment}

KA underwent various neuropsychological assessments between March 2009 and July 2015, without any noticeable change. To qualify KA's performance by reference to controls, we followed the recommendations from Spreen, Sherman \& Strauss (2006). Thus, we used the term "Superior" for scores corresponding to point estimates interval falling in the $[0.950-0.979]$ percentile range, and "Very Superior" for scores falling above that range. As shown in Table 1, KA was found to have preserved cognitive abilities in virtually all domains, except memory. For the sake of clarity, every score has been converted to percentile ranks, based on published normative data. KA had a 44point discrepancy between his memory and intelligence quotients (MQ and IQ derived from the Wechsler scales), scoring 53 and 97, respectively. After Patient HC (Hurley et al., 2011; Rosenbaum et al., 2011), this is the second greatest discrepancy between IQ and MQ ever to be reported in DA to our knowledge. An ecological assessment of memory was performed with the Rivermead Behavioral Memory Test. For the sake of comparison, results are provided in Table 2 alongside the values reported for two 
similar well-known cases: Patient Jon (Vargha-Khadem et al., 1997) and Patient HC (Rosenbaum et al., 2011). These data confirm severe anterograde amnesia in KA.

\section{INSERT TABLES 1 \& 2 HERE}

\subsection{Recall tests}

We extensively tested KA's recall abilities across different modalities, to further investigate the severity of his amnesia. Across 11 different standardized recall tests and 30 corresponding scores, KA's mean percentile rank was 3.1 . When we only considered delayed recall scores, performance dropped to a mean percentile rank of 0.1 (see Table 3).

\section{INSERT TABLE 3 HERE}

\subsection{Recognition memory tests}

Turning to recognition memory, we first administered five delayed matching-tosample (DMS) tests, keeping the testing format constant while varying the types of stimuli. These tests were also administered to 19 male control participants matched with KA for age (mean $=29.3$ years, $S D=3.2$, range $=25-35$ ), but with a slightly higher education level $($ mean $=14.8$ years, $S D=2.1$, range $=10-18)$.

First, we administered the DMS 48 test (Barbeau et al., 2004), which involves the incidental encoding of 48 colored pictures (16 abstract designs and 32 concrete pictures). After a 3-minute break filled with a verbal fluency task, participants underwent a two-alternative forced-choice recognition task. After a 1-hour break, the same two-alternative forced-choice task was administered with new foils. Second, the same procedure was used with 16 concrete words, 16 abstract words and 16 pseudo words as stimuli (verbal version of the DMS 48) using a similar procedure (we used the Lexique database (New, 2006; New, Brysbaert, Veronis, and Pallier, 2007; 
http://www.lexique.org/docLexique.php) to match words for frequency: median=6.02 per million, [0.05 - 77.3]; number of letters: median=7, [4 - 11]; number of syllables: median=2, [1 - 4]; pseudo words were also matched to words for the number of letters: median $=6$, $[5-8])$. Third, participants performed the Recognition Memory Test for Faces (Warrington, 1984).

Modified $t$ test procedures (Crawford and Howell, 1998; Crawford and Garthwaite, 2002; Crawford and Garthwaite, 2007a) revealed normal performances on all tasks (see Table 4) by KA, with the exception of the 1-hour delayed DMS 48 score, where KA failed on only two items, yielding overall accuracy of $96 \%(46 / 48)$.

We further used two four-alternative forced-choice visual recognition memory tests (Doors test; Baddeley et al., 1994) and the "Reconnaissance de dessins" subtest of the Batterie d'Efficience Mnésique 144 (BEM 144, Signoret, 1991). The latter drawings recognition test involves explicit encoding of 24 abstract black-and-white drawings, displayed one at a time for 5 seconds. After a 15-minute interval, participants had to identify each target drawing among three distractors. In both tests, Patient KA again performed within the fully normal range (see Table 4). Finally, since prior studies had suggested that the forced-choice test format may enhance recognition memory in amnesic patients compared with the old/new test format (Holdstock et al., 2002), we administered the Face Recognition subtest of the WMS-III (Wechsler, 1997). Again, KA achieved normal scores for both immediate and delayed trials (see Table 4).

\section{INSERT TABLE 4 HERE}

\subsection{Source memory}

A common feature of anterograde amnesia is the inability to perform context-rich memory tasks, where both the item but also its context of acquisition must be correctly 
recalled. We therefore adapted the item versus visual spatial memory experiment (Wolk et al., 2008) to further investigate whether Patient KA exhibited any dissociation between item-only (i.e., context-free) and item-plus-context (i.e., context-rich) memory. During an explicit encoding phase, two living and two nonliving objects were displayed on a screen, each located in one of the four quadrants (labeled 1 to 4). Participants were explicitly asked to learn the association between the nonliving objects and their location on the screen. 20 arrays of four pictures were successively presented in a self-paced manner. The recognition test started 3 minutes after the encoding phase. Participants were shown a total of 80 photographs of nonliving objects ( 40 studied, 40 novel). For each item, they were instructed to make an old/new judgment, and for each old response, the correct location of the item had to be retrieved by pressing the corresponding key. Signal detection theory (Snodgrass and Corwin, 1988) was applied to measure both discriminability ( $d$ ' index; i.e., [zHits - zFalse Alarms(FAs)]) and bias ( $C$ index; i.e., $0.5 \mathrm{x}$ [zHits $+\mathrm{zFAs}]$ ). Source memory was estimated by calculating the ratio of correct locations to hits. Patient KA and five healthy male controls underwent the experiment $($ mean age $=28.0$ years, $S D=2.1$; mean education level $=13.2$ years, $S D=$ 3.0), and modified $t$ test procedures were applied. KA performed normally in terms of accuracy (81\%), and although his $d^{\prime}$ index was impaired, owing to a higher false alarms rate, it remained at a reasonable level (Fig. 1). However, KA massively failed to recall the locations of the targets, with a source memory score of just 21\% (chance level $=25 \%$; controls' median score $>90 \%$ ).

INSERT FIGURE 1 HERE

\section{Neuroradiological findings}

\subsection{MRI examination}


Visual examination of MRI scans revealed severe bilateral atrophy of the hippocampus (see Fig. 2a). We used the VolBrain system (Manjón and Coupé, 2016) to obtain gross volumetric information about the main brain structures. As recently described in a group of children who had sustained neonatal acute respiratory failure (Cooper et al., 2015), we found a slightly lower cerebral white matter volume in KA, despite normal overall gray matter volume. The thalami and caudate nuclei, as well as the left nucleus accumbens, also showed reduced volumes, and severe bilateral hippocampal atrophy was confirmed (see Table 5). Visual comparison between a normal brain and KA's brain (see Fig. 2b) further revealed that neither the body nor the columns of the fornix were clearly discernible, and only some vestiges of the crura were identifiable. Moreover, both the mammillary bodies and the mammillothalamic tract remained unidentifiable, which is an extremely rare condition in the literature. Figure 2c illustrates additional bilateral atrophy of anterior thalamic nuclei.

\section{INSERT FIGURE 2 HERE}

\section{INSERT TABLE 5 HERE}

\subsection{Hippocampal subfields}

To further examine Patient KA's hippocampus, a dedicated high-resolution $(0.375 *$ $0.375 * 2 \mathrm{~mm}$ ) proton density-weighted MRI sequence was acquired on a 3T-scanner perpendicular to the long axis of the hippocampus. This sequence allowed us to segment the hippocampal subfields according to a protocol developed by La Joie et al. (2010) on the basis of anatomical atlases (Harding et al., 1998; Duvernoy, 2005), successfully applied to neurodegenerative disorders (La Joie et al., 2013), and which reliability has specifically been assessed recently (de Flores et al., 2015). Three subfields ( $\mathrm{CA}_{1}$, subiculum, and other subfields, i.e., $\mathrm{CA}_{2-3}$-dentate gyrus) were traced along the head and 
body of the hippocampus, based on macroscopic landmarks and heuristic geometric rules (La Joie et al., 2010). After normalizing for total intracranial volume, Patient KA's volumes were compared with those of a group of 20 healthy males who underwent the same MRI sequences, in the same scanner, and were matched for age (mean $=28.4$ years, $S D=3.4$ ), but were more educated than KA (mean education level $=14.5$ years, $S D$ = 3.0). In line with the VolBrain results, we found severe bilateral hippocampal volume loss (volume loss exceeding 55\%, $z$ score $=-5.6$ ), and further showed that volume loss was marked in every segmented subfield in both hemispheres, particularly in the $\mathrm{CA}_{1}$ and subiculum (see Fig. 3).

\section{INSERT FIGURE 3 HERE}

\subsection{Whole-brain cortical thickness}

Finally, we performed a whole-brain cortical thickness analysis of Patient KA's brain, comparing it with 10 healthy male controls aged $19-36$ years (mean $=24.2$ ), using the CorthiZon MATLAB toolbox, derived from a successful application to early Alzheimer's disease (Querbes et al., 2009). This toolbox uses a Laplace-based technique to estimate cortical thickness after segmenting the brain into 96 Brodmann areas (BAs). Cortical thickness measures were $z$-transformed to create a $z$-score map, as illustrated in Figure 4. Crawford's modified $t$ tests (Crawford and Howell, 1998; Crawford and Garthwaite, 2002) were applied to compare KA's cortical thickness values with those of controls. We found abnormally thin cortex within the left BA $34(p=0.014)$ and right BA $24(p=$ $0.041)$, as well as a trend for the left BA $30(p=0.074)$, these areas corresponding to the dorsal entorhinal cortex, anterior cingulate area, and a subdivision of the retrosplenial area, respectively. Furthermore, we found a trend toward significantly thicker cortex within the left BA $38(p=0.064)$, which corresponds to the temporal pole region. 
Importantly, no abnormal estimates of cortical thickness were found for critical subhippocampal structures within the medial temporal lobe, not least the perirhinal and ventral entorhinal cortices ( $z$ scores for bilateral BAs 35 and 36, as well as bilateral BA 28, within $1 S D$ of controls, with the exception of Right BA 28; $z$ score $=1.05$ ).

\section{INSERT FIGURE 4 HERE}

To the best of our knowledge, Patient KA is the first reported case of selective and massive damage restricted to the whole extended hippocampal system, providing a unique window onto the role of that system in learning and memory, and most importantly onto the functions of the preserved cortices in KA. In the following three sections, we therefore address three critical questions: 1) could Patient KA retrieve context-free (i.e., semantic) memories?; 2) could he access these memories in the same way as controls do?; and 3) was he able to acquire new context-free knowledge like controls?

\section{Semantic memory retrieval}

Patient KA performed a series of tasks involving the retrieval of semantic knowledge about objects, buildings, events or people listed in Table 6. All raw scores were converted to percentile ranks for the sake of clarity.

\subsection{Standard tests}

A series of individual tests or batteries of tests tapping semantic (i.e., context-free) memory was used to extensively assess Patient KA's abilities. The BECS-GRECO battery (Merck et al., 2011) is a French battery of five tests assessing semantic knowledge about objects, either living entities $(n=20)$ or manufactured objects $(n=20)$, matched on various dimensions and presented in both verbal (words) and visual (line drawings) modalities. The Mill Hill Vocabulary test (Raven, 1965) is a well-known graded-difficulty 
test requiring participants to select the correct synonym for each of 44 words (only Part B was administered) from a list of six alternatives. The EVE-30 and TOP-30 batteries (all details about these batteries available in Thomas-Antérion and Puel, 2012) include a series of tests of semantic knowledge about 30 famous public events and 30 famous people (color photographs), respectively. The EVE-30 battery involves 30 public events spanning the early 1920 's to the late 2000 's, 3 events pertaining to each decade (19201929; 1930-1939; etc.) and 9 for the last decade (2000). Each event was presented visually through a short sentence (e.g. "death of Lady Di"). Three subtests were administrated in a fixed order for each event, presented in a pre-determined random order: the evocation subtest required subjects to provide as many information as he/she could about the event; the multiple-choice recognition subtest consisted in the written presentation of three definitions of the event, the target definition together with two lure definitions, the subject being asked to select the right one (e.g. "Was the death of Lady Di 1 / the assignation of a princess by a terrorist; 2 / the death of a princess due to a car accident; 3 / the suicide of a princess?"); in the last subtest, subjects had to answer a question of detail about the event (e.g. "What was the car's brand?"); subjects also had to to point to the correct date of the event on a visual timeline. A similar logic of assessment (except for the date subtest) is used in the TOP-30 battery, but with famous faces as stimuli.

KA's performances are set out in Table 6. For the 13 scores derived from the standardized tasks, Patient KA's performances were in the high range, and it is worth noting that KA even outperformed controls on the Eve-30 and Top-30 batteries, with percentile scores above 95, reaching 99 in one subtest.

\section{INSERT TABLE 6 HERE}




\subsection{Experimental tasks}

We further designed or adapted three series of tasks to assess Patient KA's contextfree retrieval abilities for famous buildings, famous people and recent concepts. The famous buildings task featured 16 color photographs of famous buildings taken from the web and chosen during pilot testing. Participants were asked to 1) make a familiarity judgment, 2) recall the corresponding country, 3) provide as many details as they could about that building, and 4) name the item. Their responses were recorded and independently scored by two raters.

The famous people battery (SemPer battery; Laisney et al., 2009) featured 16 blackand-white photographs of famous people from different domains and 16 matched unknown faces. The latter closely matched the former on several dimensions. Participants had to 1) make a familiarity judgment for each of the 32 faces, and 2) perform a semantic matching task including an easy part (the foil celebrity had a completely different occupation from the target items) and a difficult part (all the celebrities shared the same occupation, but one foil was closer to the target, e.g., three famous politicians displayed, two belonging to the same party). The matching task was administered first with faces as stimuli, then with written names. Finally, each target face was presented again for an oral naming task.

The recent concepts questionnaire was adapted from the New Words Questionnaire developed by Thomas-Antérion et al. (2009). A total of 22 newly coined French words were selected from the Larousse dictionary. Of these, 11 entered the dictionary in 1996 or 1997, and the remaining 11 in 2006 or 2007. Since we administered the questionnaire in 2009, the use of two sets of words coined 10 years apart allowed us to look for differences when KA was asked to retrieve knowledge about the corresponding 
concepts. In amnesia, we would expect repeated exposure to new concepts for more than 10 years to lead to better performances than more recent exposure.

The 22 words were presented orally, one at a time, and participants were asked to give their best definition of each one (free recall). They then answered a multiple-choice questionnaire in which they had to choose one of three possible short definitions of each word. Finally, they were asked to decide which of two short sentences made the correct usage of each word.

Five healthy male controls matched with Patient KA for age (KA was 28 years old at the time of testing, and the healthy controls' mean age was 29 years, range: $27-30$ ), but slightly more educated (mean years of education: 12, range: 10-14), underwent these tasks, in addition to Patient KA.

The same modified $t$ test procedures as those mentioned above were used, and corresponding percentile ranks were estimated (see Table 6). For a total of 15 scores, KA's mean percentile rank was 69 , with a range of $22-88$, thus falling within the high range of controls' scores.

These results for Patient KA confirmed prior studies (Kensinger et al., 2001; Schmolck et al., 2002; O’Kane et al., 2004). However, our tasks did not allow us to speculate about how KA actually accessed these context-free memories. It may be that, as previously suggested for Patient Jon (Bird et al., 2008), KA made use of idiosyncratic strategies to access semantic memories, and/or this access, though quantitatively normal, was far slower than that of controls. In the following series of experiments, we therefore sought to strongly constrain the way KA could retrieve semantic memories, to investigate whether he would still perform normally. 


\section{Speeded semantic memory retrieval}

The following series of three experiments were adapted from Besson et al. (2017). Participants for these three experiments were 13 right-handed men (mean age $=25$ years, range $=22-27 ;$ mean education level $=15$ years, range $=12-21)$. Patient KA was 32 years old at the time of these experiments, and thus slightly older and less educated than the controls.

\subsection{Experimental setting}

For all experiments, stimuli were presented on a CRT computer screen, using E-Prime 2.0 software (http://www.pstnet.com/eprime.cfm, E-Prime, RRID: SCR_009567). Participants responded by raising their fingers from a dedicated infrared response pad, and the need for a speedy response was always emphasized in the instructions.

\subsection{General method: speed and accuracy boosting (SAB) procedure}

The speed and accuracy boosting (SAB) procedure was introduced by Besson et al. (2012) to constrain participants to use their fastest strategy, and has been used in several studies (Barragan-Jason et al., 2013; Besson et al., 2015; Besson et al., 2017). Based on a classic go/nogo task, the SAB procedure constrains participants to provide a go response for targets within a given response time following stimulus onset. The deadline was set at $600 \mathrm{~ms}$ in the present experiments, based on previous studies. A go response before this deadline was followed by audio feedback, which was positive if the item was a target (hit), and negative if the item was a distractor (FA). Similarly, a no-go response was followed by either positive (correct no-go response for a distractor, i.e., correct rejection) or negative (incorrect no-go response for a target, i.e., omission) audio feedback. Before each item was presented, a fixation cross was displayed with a jittered 
duration ranging from 300 to $600 \mathrm{~ms}$. Stimuli were flashed for $100 \mathrm{~ms}$, after which participants had up to $500 \mathrm{~ms}$ to give their answer. Each of the following experiments comprised two consecutive blocks of 140 items. As the SAB procedure is a very demanding task, two training blocks where 10 target stimuli had to be recognized among 10 distractors preceded each block for each experiment.

The SAB procedure provides a continuous distribution of responses times, allowing the minimum reaction time (minRT) for recognition to be estimated (see below). As recognition memory is known to rely upon two processes (recollection and familiarity), and as familiarity is supposed to be a rapid and automatic process, in contrast to the slow, controlled processes that support recollection (Brown and Aggleton, 2001; Yonelinas, 2002), the SAB procedure is assumed to rely mainly on familiarity (Sauvage et al., 2010; Besson et al., 2012).

\subsection{Experiment 1: Speeded go/no-go human face categorization task}

We took 140 photographs of unknown faces and 140 photographs of animal faces from the web. We then selected 70 pictures of each kind to build two lists of 140 stimuli. Upright and inverted presentations were randomly assigned to the lists (half inverted, half upright). Participants were told that the human faces were the targets (go responses), and the animal faces the distractors (no-go responses).

\subsection{Experiment 2: Speeded go/no-go famous face recognition task}

We took 140 photographs of unknown faces and 140 photographs of famous faces from the web. Famous faces were selected on the basis of pilot studies showing that they were recognizable to healthy individuals the same age as KA. Unknown faces were selected because they looked like they could be famous faces (attractiveness and quality of the photographs), and were matched to the famous faces for sex, head orientation and emotional expression. We then selected 70 pictures of each kind to build two lists of 140 
stimuli. Again, upright and inverted images were randomly assigned to the lists as in Experiment 1. Participants were told that the famous faces were the targets (go responses), and the unknown faces the distractors (no-go responses).

\subsection{Experiment 3: Speeded go/no-go individual face recognition task}

We took 140 photographs of two French celebrities from the web: 70 photographs of former French President Nicolas Sarkozy and 70 photographs of the famous and now deceased French singer Johnny Hallyday. Two sets of 70 photographs of unknown faces were then selected from the web so that they matched the famous photographs as closely as possible (i.e., each unknown face looked like it could be famous, had the same orientation, emotion, hair color, apparent age, etc.). This resulted in two lists of 140 photographs. Upright and inverted images were randomly assigned to the lists as before, i.e. 70 items upright and 70 inverted within each list. Participants were given the name of a celebrity (i.e., either Nicolas Sarkozy or Johnny Hallyday) and told that the photographs of that celebrity were the targets (go responses), and the unknown faces the distractors (no-go responses).

\subsection{Analyses}

Performances were analyzed according to signal detection theory (Snodgrass and Corwin, 1988): correct go responses were regarded as hits, and incorrect go responses as FAs, thus providing measures of discriminability ( $d^{\prime}$ index) and bias ( $C$ index), both indices being corrected according to Snodgrass and Corwin (1988). We applied $\chi^{2}$ tests $(p<0.05)$ to hits and FAs for targets and distractors to determine whether participants successfully performed each task. As stated earlier, the SAB procedure provides a continuous distribution of response times, allowing the minimum processing time required for each task to be estimated. The minRT was computed as the latency at which the number of hits started to significantly outnumber the number of FAs. For each 
participant, we used Fisher's exact test $(p<0.05)$ with 40 -ms time bins to determine whether the hit-to-FA ratios differed significantly. Some participants had low overall performances (i.e., low $d^{\prime}$ index), when hit and FA distributions tended to overlap, meaning that their minRT could not be computed. Patient KA's performances were compared with those of controls using the modified $t$ test procedure.

\section{INSERT FIGURE 5 HERE}

\subsection{Results}

Figure 5 illustrates Patient KA's performances on all three experiments. $\mathrm{He}$ successfully performed each and every task, despite the strict time constraints (all $\chi^{2}$ tests yielded $p$ values $>0.05$ ). For upright stimuli, Patient KA exhibited normal discriminability between targets and distractors in all the tasks, and strikingly even outperformed controls on the famous face recognition experiment, achieving a $d^{\prime}$ of 2.17 (controls' mean $d^{\prime}=0.711$, range $=0-1.053, t=5.204, p<0.01$ ). Regarding bias, Patient KA again had normal $C$ indices, with the exception of the human face categorization task, where he proved to be more conservative than controls. Regarding minRTs for upright stimuli, four controls performed too poorly on the famous face recognition task to achieve a minRT. By contrast, Patient KA achieved a normal minRT and even outperformed controls on the famous face recognition experiment, with a minRT of 360 $\mathrm{ms}$ (controls' mean $=489$, range $=400-560, t=-2.22, p<0.05)$. Furthermore, Patient KA had a minRT of $280 \mathrm{~ms}$ in the inverted stimulus condition of the individual face recognition task, again outperforming controls (controls' mean $=354 \mathrm{~ms}$, range $=$ $280-400, t=-3.43, p<0.01)$.

When we considered the inverted stimulus results, we found that Patient KA and controls did not differ on either discriminability performances or bias (all $p \mathrm{~s}>0.05$; see 
Fig. 5). Moreover, the inversion effect on performances was similar in both Patient KA and controls.

The following experiment assessed whether KA could explicitly acquire and retrieve new context-free knowledge as well as controls.

\section{Speeded learning of new knowledge}

Control participants for the following experiment were eight right-handed men matched with Patient KA for age but more educated (mean age $=28$ years, range $=22-$ 34 ; mean education level $=19$ years, range $=14-21$ ). Patient KA was 31 years old when he performed this experiment.

\subsection{Experimental setting and stimuli}

The experimental setting and analyses were the same as those described above for the SAB procedure. The stimulus set consisted of 280 color photographs of easily nameable objects. The experiment required participants to explicitly learn blocks of 30 pictures of items and to recognize them among distractors after an interval of 3 minutes. The rationale behind using pictures of objects rather than faces as in the first three experiments was that faces are regarded as having a particular status in amnesia. Research has consistently shown that unfamiliar face recognition can be preserved after hippocampal damage (Aggleton and Shaw, 1996; Carlesimo et al., 2001; Cipolotti et al., 2006; Bird et al., 2007; Taylor et al., 2007; Bird et al., 2008; Bird and Burgess, 2008; Aly et al., 2010; Smith et al., 2014; Bird, 2017; but see Coleshill et al., 2004; Kafkas et al., 2017 for divergent findings). As our aim here was to assess whether Patient KA could acquire new context-free knowledge normally, we wished to rule out any materialspecific account of either preserved or impaired new learning. 


\subsection{Experimental procedure}

Participants were shown 120 pictures of objects, one at a time, across four 30 -item blocks of explicit study. Each time, the instructions emphasized the need to remember each photograph for subsequent recognition. After each study block, participants had to watch a 3-minute cartoon randomly chosen from a set of 12 different videos. Following this interference phase, participants were given the instructions for the test blocks. During these blocks, the 30 target pictures were randomly mixed with 30 distractor pictures. Participants had $600 \mathrm{~ms}$ to answer, in line with previous studies. Participants were instructed to provide go responses for old items, and no-go responses for new items as quickly as possible.

Given the difficulty of this task, even for healthy young controls, two study blocks of 10 target items and two test blocks with 10 target pictures mixed with 10 distractors were used as practice trials for each participant. None of these 40 pictures were used in any of the subsequent study and test trials. These practice trials generally had to be repeated, to allow participants to become accustomed to the task's speed constraints.

\section{INSERT FIGURE 6 HERE}

\subsection{Results}

Results are displayed in Figure 6. Patient KA correctly discriminated between targets and lures, with a $d^{\prime}$ index of 1.20 , which fell within the low-to-normal range of controls ( $z$ score $=-1.41, t=-1.329, p=0.226)$. He exhibited a response bias, in that he tended to be more conservative than controls (Patient $\mathrm{KA}=-0.54, z$ score $=-2.00, t=-1.89, p=$ 0.06). One interesting possibility is that Patient KA's discriminability may have been underestimated because of his tendency to be more conservative (i.e. he tended to give fewer go responses overall). We therefore used a regression approach adapted to single- 
case analyses (Crawford and Garthwaite, 2007b) to roughly estimate the range of $d^{\prime}$ index values expected for a given response bias. Patient KA's $C$ index $(-0.54)$ predicted a $d^{\prime}$ index of $2.5(S E=0.66)$, which tended to be significantly better than the $d^{\prime}$ index that was actually found for KA $(1.20, z=-3.8, p=0.06)$. The conservative bias we observed in Patient KA may therefore have led to an underestimation of his actual discriminability abilities.

Regarding response times, Patient KA's median response time was significantly shorter than that of controls (median RT $=398 \mathrm{~ms}$, controls' mean $=469 \mathrm{~ms}$, range $=$ 432-499, $t=-2.91, p<0.05)$, but he did not differ from controls on minRT (KA $=390 \mathrm{ms,}$ controls' mean $=420 \mathrm{~ms}$, range $=390-450, t=-1.01, p=0.35$ ).

\section{Discussion}

We report the case of Patient KA, who has early-onset amnesia characterized by extremely rare selective and massive damage to each component of the extended hippocampal system. We found that Patient KA displayed few, if any, residual episodic abilities. However, not only was he able to accurately retrieve semantic memories, but he was also the first patient to show clear evidence of superior or even very superior access to these memories. Even more strikingly, KA performed faster and more accurately than controls on identifying famous faces, despite very strict speed constraints. In addition, we found evidence for preserved abilities of new knowledge acquisition in KA, again in the context of a speed-constraint paradigm limiting the range of available learning strategies. These findings suggest that under certain circumstances, a very powerful and efficient learning system can allow new knowledge to be acquired independently of any episodic support. Finally, we performed the first ever cortical thickness analysis in DA. This yielded novel findings suggesting profound functional 
reorganization of the brain in Patient KA. Although we have yet to establish the exact nature of the system preserved in KA and how it developed, the present results are extremely valuable, not least from a clinical perspective.

\section{A case of selective and massive damage to the extended hippocampal system}

Since 1997, when Vargha-Khadem and colleagues first described cases of DA, case studies have mainly focused on hippocampal atrophy, with a typical $30-40 \%$ bilateral reduction (Vargha-Khadem et al., 2001). Until very recently, little was known about the status of the other brain structures, either within or outside the MTL. As stated in the Introduction, evidence for extrahippocampal damage was rather sparse, but suggested that structures like the putamen, brainstem, thalamus and retrosplenial cortex might be affected (Gadian et al., 2000; Vargha-Khadem et al., 2003; Rosenbaum et al. 2011). Importantly, abnormalities of the mammillary bodies and the fornix were described in Patients VJ and HC (Bindschaedler et al., 2011; Olsen et al., 2013; Rosenbaum et al., 2014). Quite recently, a group study found that mammillary body atrophy was present in $66 \%$ of participants with DA, and there was a mild reduction in thalamus volumes at the group level (Dzieciol et al., 2017). This research confirmed that in DA, damage probably extends far beyond the hippocampal formations, and may include some other components of the extended hippocampal system, with an apparent variability between patients. Our findings for KA suggest that the entire hippocampal system is compromised, and not just some components.

Hippocampal subfield segmentation indicated severe and homogeneous impairment of hippocampal development across each and every subfield, extending beyond the $\mathrm{CA}_{1}$ subfield as one might expect following hypoxia (Kawasaki et al., 1990). Hippocampal subfield volumetry has only been reported once in DA (Patient HC; Olsen et al., 2013), 
and this study also pointed to damage beyond the $\mathrm{CA}_{1}$ subfield. However, KA's hippocampal atrophy was fully symmetrical compared with that of Patient HC, who was found to have relative preservation of the $\mathrm{CA}_{2-3}$-dentate gyrus subfields in the left hemisphere. Atrophy was very severe in KA: the volumes we measured were below the lowest measures of the 20 controls, and volume reduction exceeded 55\%. Patient KA therefore exhibited the most severe hippocampal atrophy of all reported DA cases.

The hippocampus was not the only structure to be severely atrophied in KA. We also report evidence for severe bilateral atrophy of the fornix, as well as an apparent absence of mammillary bodies. Complete agenesis of the mammillary bodies is an extremely rare condition (but see Patient HC, Rosenbaum et al., 2014). Moreover, we failed to visually identify the mammillothalamic tract in KA, suggesting complete agenesis of this tractus, which has not previously been reported, to the best of our knowledge. Thalamus volumetry also showed significant bilateral atrophy. Last, whole-brain cortical thickness analyses in KA revealed thinner left dorsal entorhinal, left retrosplenial and right anterior cingulate cortices. The whole extended hippocampal system was therefore compromised in KA. It is noteworthy that Patient KA and Patient HC were found to have atrophy of the left and right retrosplenial cortices, respectively. Vann and Albasser (2009) argue that the retrosplenial cortex may be the target of covert lesions after damage to the hippocampal/mammillothalamic system (see also Aggleton, 2008). This region is thought to play a specific role in episodic learning and retrieval, beyond its acknowledged function linking the anterior thalamus nucleus and hippocampus. Evidence of an abnormal retrosplenial cortex in DA therefore reinforces findings of damage extending well beyond the hippocampal formation.

Such extensive injury, together with hippocampal subfield atrophy extending beyond $\mathrm{CA}_{1}$, raises the question of the potential combined effects of an additional etiology (see 
Rosenbaum et al., 2014), and of complex patterns of antero- and retrograde degeneration following early injury (e.g. Caine and Watson, 2000; Loftus et al., 2000). Nonetheless, hypoxia remains the main probable cause, as recently suggested in Cooper et al. (2015)'s case series.

By contrast, in line with previous studies (Vargha-Khadem et al., 1997; Gadian et al., 2000; Vargha-Khadem et al., 2003; Brizzolara et al., 2003; Martins et al., 2006; Bindschaedler et al., 2011; Olsen et al., 2013), we found that subhippocampal structures (perirhinal, entorhinal and parahippocampal cortices) were preserved in KA.

To the best of our knowledge, Patient KA represents the first reported example in humans of such severe damage extending to each and every structure of the hippocampal system. This system is therefore highly unlikely to be functional. If, as Aggleton and Brown (1999) and Aggleton et al. (2010) suggest, this system is the core brain network underlying episodic learning, the patterns of both preserved and impaired memories in Patient KA are of considerable interest.

\section{A case of knowledge acquisition without episodic learning}

As stated in the Introduction, prior reports of patients with amnesia consistently showed preserved semantic memory retrieval despite compromised episodic memory, the most striking results coming from patients with DA. However, evidence for preserved semantic knowledge relied upon very limited assessments-mainly tests of academic skills like the Vocabulary and Information subtests of the WAIS, where patients typically perform in the low-to-normal range. This is of great importance, as it has been pointed out that some residual level of episodic learning abilities may allow patients-given sufficient time and repetition-to reach close-to-normal levels of knowledge (see Squire and Zola, 1998). Interestingly, Kan et al. (2009) suggested that in 
cases of adult-onset amnesia where key brain structures for the semantic system are preserved (anterior and lateral parts of the temporal lobes), prior knowledge about tobe-learned items enhances some residual episodic learning. Thus, in cases of early-onset amnesia, any residual episodic learning ability may allow, after sufficient repetition, the acquisition of a limited but substantial amount of semantic knowledge, which may, in turn, boost further learning, leading to the putative semantic-episodic distinction reported in prior DA cases. Accordingly, previous investigations of new learning (rather than semantic retrieval) in DA have shown that patients' performances critically rely on the number of repetition trials (Brandt et al., 2006; Gardiner et al., 2006 Martins et al., 2006).

Episodic learning in Patient KA was clearly close to zero, with delayed recall scores for a wide variety of stimuli at floor level, and immediate source memory performances also at chance level. In many tasks, we showed that KA did indeed perform more poorly than most previous DA cases. These findings clearly demonstrate that little, if any, residual episodic learning could occur in KA. Even so, his memories about public events, famous people, objects and famous buildings, as well as his lexical knowledge for concepts coined only 2-3 years before testing, were found to be in the normal, superior, or even very superior range. KA indeed outperformed controls on some tasks involving the recall and forced-choice recognition of famous people and public events. It is hard to see how a slow, inefficient and gradual process of episodic learning can lead to this pattern of semantic memory performances. One limitation that must be mentioned here is the absence of control for media exposure, which may have altered the results (Kapur, Thompson, Kartsounis, Abbot, 1999). However, across multiple interviews with the patient and his family, and across several meetings at the patient's home, we did not collect any information that may suggest that KA differs from people of his age regarding 
media exposure. More specifically, the patient reads the newspaper several times a week, and watches TV once a day, which falls in the normal range in France. Our findings for KA are therefore difficult to explain without making the assumption of some functional distinction within declarative memory.

We sought to control for the range of processes involved in semantic memory retrieval, in order to explore whether this apparent preservation of semantic knowledge in KA could be the result of alternative, putatively abnormal, strategies (Gardiner et al., 2006; see also Bird et al., 2008, in Patient Jon). To this end, we carried out a series of recognition experiments featuring time constraints, which greatly limited the range of possible strategies. Experiments 2 and 3 (Section 5) involved the detection and identification of famous faces, respectively. We argue that these tasks could only be successfully performed if a normal representation of each famous face had been built across prior encounters. Moreover, the identification experiment (Exp. 3) further required these representations to include sufficiently detailed visual knowledge for the celebrity to be distinguished from the foils. The fact that KA outperformed controls on both speed and accuracy in Experiment 2, and performed at the controls' level in Experiment 3, strongly supports the idea that not only did he have normal access to context-free knowledge for faces, but also that the representations he had built of these faces were quite similar to those of controls. The normal reductions in accuracy observed in KA when inverted faces were used, further supports this interpretation, suggesting that the holistic processing of faces had similar costs for KA and for controls (Rossion, 2008). However, we acknowledge that both experiments 2 and 3 can be achieved at a pre-semantic level, on the basis of "Face Recognition Units" (FRUs) activation solely within a typical face-processing framework (Bruce and Young, 1986). Nonetheless, we argue that these tasks can inform us about the stored context-free, or 
semantic, knowledge in patient KA, for several reasons. First, the fact that patient KA succeeds in Experiment 3 and outperforms controls in the Experiment 2, despite suffering amnesia from birth, is in itself a surprising finding. This result might indicate that some learning system independent of the hippocampal system has allowed the building of context-free knowledge about faces at least as efficiently as controls do. The fact that KA outperformed controls in the "TOP-30" task involving famous faces as stimuli strengthens this idea. Second, the most recent revision of the Bruce and Young framework (Burton, Bruce and Johnson, 1990) adds the "Semantic Information Units" (SIUs) to the above-mentioned FRUs. Within that framework, SIUs activation is expected to result in faster recognition for faces with pre-experimental knowledge like the famous faces we used in Experiment 2 (e.g. Herzmann and Sommer, 2010). The fact that Experiment 2 yielded slower RTs than face categorization (Experiment 1) and individual face recognition (Experiment 3) strengthens the idea that late processing stages are involved in the task. While controls reached min RTs around $490 \mathrm{~ms}$ and a median d' around 0.85 , patient KA was on average $100 \mathrm{~ms}$ faster and far more accurate $\left(d^{\prime}>2.0\right)$ (see Figure 5). We therefore speculate that such an unexpected finding can be at least partly explained by the overreliance of the patient KA on his preserved semantic knowledge (i.e. SIUs) to make familiarity decisions, thus abnormally speeding up his RTs within the Famous Face Recognition task. Future work is however clearly needed to assess more directly the acquisition of semantic knowledge in patients with developmental amnesia (Blumenthal et al., 2017 for a recent report).

Taken together, the results of these experiments speak for normal-to-very-superior abilities in Patient KA for retrieving semantic memories.

Regarding the acquisition of new explicit knowledge, rather than its retrieval, we found that strict speed constraints did not prevent Patient KA from performing just as 
fast and as accurately as controls (see Section 6). Strikingly, Patient KA even had shorter median reaction times during the test phase, and his minRT was within the controls' shorter range, suggesting that the cognitive processes associated with the judgment of prior occurrence for newly learned material were at least as efficient in KA as they were in controls. This was not achieved after extensive repetition trials, but after a single study trial. It is noteworthy that when he gave go responses to targets, KA proved to be just as fast as controls, strongly supporting the idea that he used fast, automatic, familiarity-based processes.

In summary, despite no evidence for any residual context-rich memories, Patient KA was able to acquire normal or superior levels of context-free memories just as efficiently as controls, independently of the modalities or kinds of concepts we explored in the present study. It is unclear for the time being how he acquired such massive amount of knowledge. Given that he has no episodic memory, he necessarily uses learning strategies that are different from healthy subjects who can use their episodic memory whenever they learn new facts. However, it is very unlikely that his abilities can be explained in terms of residual episodic abilities, and instead it supports the theoretical assumptions that episodic learning is not a prerequisite for semantic knowledge acquisition. Further understanding of how such a powerful learning system could be so efficient in $\mathrm{KA}$ is warranted, given the opportunities it might bring for the rehabilitation of amnesic patients. Apart from controversial findings of rapid arbitrary learning in four amnesic patients that presumably resulted from the so-called fast-mapping mechanism (Sharon et al., 2011), we are not aware of any previous findings suggesting normal knowledge acquisition in amnesia without extensive repetition and/or dedicated learning techniques. 


\section{Cortical thickness in KA: an explanation for his superior semantic memories?}

We found that left temporal pole cortices tended to be thicker in Patient KA, while we observed thinner cortices within structures of the extended hippocampal system. Given the critical role of the left anterior temporal lobe in semantic or context-free memories (e.g., Jefferies, 2013; Lambon Ralph, 2014; Guido, 2017), and prior well-known studies relating higher brain volumes to superior abilities or expertise (e.g. Woolett and Maguire, 2011), this requires further discussion.

Cortical thickness is a relevant measure when investigating neurodevelopmental disorders, as it is thought to reflect both synaptogenesis and synaptic pruning, two major maturation processes of the brain (Huttenlocher, 1990; Gogtay et al., 2007; Khundrakpam et al., 2016). Surprisingly, we did not find any prior cortical thickness analyses for DA. Nonetheless, neonatal anoxia-hypoxia has been found to have a specific impact on cortical thinning within medial temporal regions (Bregant et al., 2013; see also Phillips et al., 2011; Zubiaurre-Elorza et al., 2012, for the specific influence of preterm birth on regional cortical thinning patterns). In Patient KA, we found abnormally thin cortices in regions supposed to follow a cubic developmental trajectory, with an initial rapid increase in thickness followed by an asymptotic decrease (i.e., right cingulate cortices), and thicker cortex within the left temporal pole, a region supposed to follow a quadratic trajectory (i.e., inverted U-shaped curve; Shaw et al., 2008). We can therefore speculate that neonatal hypoxia in KA may have altered the developmental trajectory of cortical thickness, leading to functional reorganization within extrahippocampal structures (for evidence in monkeys and humans, see Lavenex et al., 2007; Braun et al., 2008). Interestingly, the morphology of the temporal pole has already been associated to extraordinary memory performance in subjects with Highly Superior Autobiographical Memory (HSAM). These subjects are able to recall with very high 
accuracy a large amount of events of their own past, including days and dates when they occurred (Parker, Cahill \& McGaugh, 2006). LePort et al. (2012) have shown that a sample of HSAM subjects presented with lower estimates of grey matter density in the bilateral temporal poles (i.e. Brodmann Area 38). Thus, while HSAM is characterized by very superior autobiographical episodic memory but average levels of declarative memory otherwise, including semantic memory, KA presents with dramatically impaired autobiographical episodic memory but superior to very superior semantic knowledge. It is therefore tempting to consider the possibility that the neuronal plasticity within the area of the temporal poles plays a critical role in the differential development of episodic autobiographical and semantic memories.

However, as stated above, borderline or low-average ranges of performances across semantic knowledge tasks are the rule in DA. Evidence for very superior explicit memory in KA was therefore unexpected (but see Kapur, 2011, for an extensive review and discussion of such paradoxical profiles). Whereas bilateral hippocampal atrophy typically does not exceed $30-40 \%$, it was more than $50 \%$ in KA. A similar counterintuitive finding of better performance despite more severe damage had already been reported (Murray and Mishkin, 1998; Baxter and Murray, 2001; see also Heuer and Bachevalier, 2011; in humans, see Barbeau et al., 2005; but see Zola and Squire, 2001). For example, using DMS procedures, greater impairment in recognition memory following smaller hippocampal lesions has been highlighted in monkeys (Murray and Mishkin, 1998). These authors suggested that in the case of mild hippocampal damage, for example, irrelevant signal processing coming from that partly inefficient subsystem may compete with the relevant physiological signal processing from preserved surrounding subsystems. Earlier studies in monkeys had suggested that the amount of hippocampal damage required to produce a significant deficit in DMS tasks is around 
$20 \%$ (Zola and Squire, 2001), which is close to the suggested $20-30 \%$ cut-off reported by Isaacs et al. (2003) for a DA syndrome. Thus, an interesting hypothesis that requires further investigation -possibly in a group study- is that an inverted (convex) quadratic function characterizes the relationship between the degree of context-free memory preservation and the amount of damage to the hippocampal system or the thickness of temporal neocortical areas in DA.

\section{Conclusion}

We have reported the case of Patient KA, who has developmental amnesia, and was found to have damage beyond the hippocampus itself, encompassing the whole of the extended hippocampal system. As expected, KA was densely amnesic, with no evidence of residual episodic learning abilities. Despite this, he had normal-to-very-superior semantic knowledge, and was able to retrieve that knowledge with the same speed and accuracy as controls. Besides, new explicit learning was found to be possible in for KA, again within the fully normal range regarding accuracy and speed, even under strong strict temporal time constraints. Our findings are consistent with the existence of a functional dissociation, (or division of labor), for declarative memory within the medial temporal lobes. Importantly, they add to the growing body of evidence suggesting that rapid learning may occur outside the hippocampus. However, we have yet to fully understand how such rapid, explicit, learning can occur and be promoted in amnesic patients. 


\section{Acknowledgments}

We are very grateful to Patient KA for his enthusiasm and tenacity. We are indebted to KA's parents for their participation in providing key elements of KA's early development. We are also grateful to Dr Eduardo Pasqualini for his visual analysis of KA's hippocampi and for his insightful commentaries on this case. KA and his parents gave their explicit consent for the publication of this case study. The authors of the present study have no conflict of interest to declare. 


\section{$\underline{\text { References }}$}

Aggleton, J. P. (2008). EPS Mid-Career Award 2006. Understanding anterograde amnesia: Disconnections and hidden lesions. Quarterly Journal of Experimental Psychology, 61(10), 1441-1471. http://doi.org/10.1080/17470210802215335

Aggleton, J. P., \& Brown, M. W. (1999). Episodic memory, amnesia, and the hippocampalanterior thalamic axis. Behavioral and Brain Sciences, 22(3), 425-444; discussion 444-489. http://doi.org/10.1017/S0140525X99002034

Aggleton, J. P., O’Mara, S. M., Vann, S. D., Wright, N. F., Tsanov, M., \& Erichsen, J. T. (2010). Hippocampal-anterior thalamic pathways for memory: Uncovering a network of direct and indirect actions. European Journal of Neuroscience. http://doi.org/10.1111/j.1460-9568.2010.07251.x

Aggleton, J. P., \& Saunders, R. C. (1997). The relationships between temporal lobe and diencephalic structures implicated in anterograde amnesia. Memory, 5(1-2), 49-71. http://doi.org/10.1080/741941143

Aggleton, J. P., \& Shaw, C. (1996). Amnesia and recognition memory: A re-analysis of psychometric data. Neuropsychologia, 34(1), 51-62. http://doi.org/10.1016/00283932(95)00150-6

Aly, M., Knight, R. T., \& Yonelinas, A. P. (2010). Faces are special but not too special: Spared face recognition in amnesia is based on familiarity. Neuropsychologia, 48(13), 3941-3948. http://doi.org/10.1016/j.neuropsychologia.2010.09.005

Baddeley, A., Emslie, H., Nimmo-Smith, I. (1994). Doors and People. Thames Valley Test Company.

Barbeau, E., Didic, M., Tramoni, E., Felician, O., Joubert, S., Sontheimer, A., ... Poncet, M. (2004). Evaluation of visual recognition memory in MCI patients. Neurology, 62(8), 1317-1322. Retrieved from http://www.ncbi.nlm.nih.gov/pubmed/15111668

Barbeau, E. J., Felician, O., Joubert, S., Sontheimer, A., Ceccaldi, M., \& Poncet, M. (2005). Preserved visual recognition memory in a amnesic patient with hippocampal lesions. Hippocampus, 15(5), 587-596. http://doi.org/10.1002/hipo.20079

Barragan-Jason, G., Besson, G., Ceccaldi, M., \& Barbeau, E. J. (2013). Fast and famous: Looking for the fastest speed at which a face can be recognized. Frontiers in 
Psychology, 4, 1-10. http://doi.org/10.3389/fpsyg.2013.00100

Baxter, M. G., \& Murray, E. A. (2001). Effects of hippocampal lesions on delayed nonmatching-to-sample in monkeys: A reply to Zola and Squire (2001). Hippocampus, 11(3), 201-203. http://doi.org/10.1002/hipo.1037

Bayley, P. J., \& Squire, L. R. (2002). Medial temporal lobe amnesia: Gradual acquisition of factual information by nondeclarative memory. J Neurosci, 22(13), 5741-5748. http://doi.org/20026545

Bayley, P. J., \& Squire, L. R. (2005). Failure to acquire new semantic knowledge in patients with large medial temporal lobe lesions. Hippocampus, 15(2), 273-280. http://doi.org/10.1002/hipo.20057

Besson, G., Barragan-Jason, G., Thorpe, S. J., Fabre-Thorpe, M., Puma, S., Ceccaldi, M., \& Barbeau, E. J. (2017). From face processing to face recognition: Comparing three different processing levels. Cognition, 158, 33-43. http://doi.org/10.1016/j.cognition.2016.10.004

Besson, G., Ceccaldi, M., Didic, M., \& Barbeau, E. J. (2012). The speed of visual recognition memory. Visual Cognition, 20(10), 1131-1152. http://doi.org/10.1080/13506285.2012.724034

Besson, G., Ceccaldi, M., Tramoni, E., Felician, O., Didic, M., \& Barbeau, E. J. (2015). Fast, but not slow, familiarity is preserved in patients with amnestic mild cognitive impairment. Cortex, 65, 36-49. http://doi.org/10.1016/j.cortex.2014.10.020

Bindschaedler, C., Peter-Favre, C., Maeder, P., Hirsbrunner, T., \& Clarke, S. (2011). Growing up with bilateral hippocampal atrophy: From childhood to teenage. Cortex. http://doi.org/10.1016/j.cortex.2010.09.005

Bird, C. M. (2017). The role of the hippocampus in recognition memory. Cortex, 155-165. http://doi.org/10.1016/j.cortex.2017.05.016.This

Bird, C. M., \& Burgess, N. (2008). The Hippocampus Supports Recognition Memory for Familiar Words but Not Unfamiliar Faces. Current Biology, 18(24), 1932-1936. http://doi.org/10.1016/j.cub.2008.10.046

Bird, C. M., Shallice, T., \& Cipolotti, L. (2007). Fractionation of memory in medial temporal lobe amnesia. Neuropsychologia, 45(6), 1160-1171. 
http://doi.org/10.1016/j.neuropsychologia.2006.10.011

Bird, C. M., Vargha-Khadem, F., \& Burgess, N. (2008). Impaired memory for scenes but not faces in developmental hippocampal amnesia: A case study. Neuropsychologia, 46(4), 1050-1059. http://doi.org/10.1016/j.neuropsychologia.2007.11.007

Blumenthal, A., Duke, D., Bowles, B., Gilboa, A., Rosenbaum, R. S., Köhler, S., \& McRae, K. (2017). Abnormal semantic knowledge in a case of developmental amnesia. Neuropsychologia, 102(June), 237-247. http://doi.org/10.1016/j.neuropsychologia.2017.06.018

Brandt, K. R., Gardiner, J. M., Vargha-Khadem, F., Baddeley, A. D., \& Mishkin, M. (2006). Using semantic memory to boost "episodic" recall in a case of developmental $\begin{array}{lll}\text { amnesiar } & \text { Neuroreport, 17(10), 1057-1060. }\end{array}$ http://doi.org/10.1097/01.wnr.0000220134.09221.04

Braun, M., Finke, C., Ostendorf, F., Lehmann, T. N., Hoffmann, K. T., \& Ploner, C. J. (2008). Reorganization of associative memory in humans with long-standing hippocampal damage. Brain, 131(10), 2742-2750. http://doi.org/10.1093/brain/awn191

Bregant, T., Rados, M., Vasung, L., Zadnik, V., Derganc, M., Evans, A. C., ... Kostovic, I. (2013). Brain volume reduction in young adults with perinatal hypoxic-ischaemic encephalopathy. European Journal of Paediatric Neurology, 17, Supplement, S10S11. http://doi.org/http://dx.doi.org/10.1016/S1090-3798(13)70034-5

Brizzolara, D., Casalini, C., Montanaro, D., \& Posteraro, F. (2003). A case of amnesia at an early age. Cortex, 39(4-5), 605-625. http://doi.org/http://dx.doi.org/10.1016/S0010-9452(08)70856-6

Brown, M. W., \& Aggleton, J. P. (2001). Recognition memory: What are the roles of the perirhinal cortex and hippocampus? Nature Reviews Neuroscience, 2(1), 51-61.

Bruce, V., \& Young, A. W. (1986). Understanding face recognition. British Journal of Psychology, 77, 305-327. http://doi.org/10.1111/j.2044-8295.1986.tb02199.x

Burton, A. M., Bruce, V., \& Johnston, R. A. (1990). Understanding face recognition with an interactive activation model. British Journal of Psychology, 81,361-380. http://doi.org/10.1111/j.2044-8295.1990.tb02367.x 
Caine, D., \& Watson, J. D. G. (2000). Neuropsychological and neuropathological sequelae of cerebral anoxia: A critical review. Journal of the International Neuropsychological Society, 6(1), 86-99. http://dx.doi.org/10.1017/S1355617700611116

Carlesimo, G. A., Fadda, L., Turriziani, P., Tomaiuolo, F., \& Caltagirone, C. (2001). Selective sparing of face learning in a global amnesic patient. Journal of Neurology, Neurosurgery, and Psychiatry, 71, 340-346. http://doi.org/10.1136/jnnp.71.3.340

Cipolotti, L., Bird, C., Good, T., Macmanus, D., Rudge, P., \& Shallice, T. (2006). Recollection and familiarity in dense hippocampal amnesia: A case study. Neuropsychologia, 44(3), 489-506. http://doi.org/10.1016/j.neuropsychologia.2005.05.014

Coleshill, S. G., Binnie, C. D., Morris, R. G., Alarcon, G., van Emde Boas, W., Velis, D. N., ... van Rijen, P. C. (2004). Material-Specific Recognition Memory Deficits Elicited by Unilateral Hippocampal Electrical Stimulation. The Journal of Neuroscience, 24(7), 1612-1616. http://doi.org/10.1523/JNEUROSCI.4352-03.2004

Cooper, J. M., Gadian, D. G., Jentschke, S., Goldman, A., Munoz, M., Pitts, G., ... VarghaKhadem, F. (2015). Neonatal hypoxia, hippocampal atrophy, and memory impairment: Evidence of a causal sequence. Cerebral Cortex, 25, 1469-1476.. http://doi.org/10.1093/cercor/bht332

Crawford, J. R., \& Garthwaite, P. H. (2002). Investigation of the single case in neuropsychology : confidence limits on the abnormality of test scores and test score differences. Neuropsychologia, 40, 1196-1208.

Crawford, J. R., \& Garthwaite, P. H. (2007a). Comparison of a single case to a control or normative sample in neuropsychology: Development of a Bayesian approach. Cognitive $\quad$ Neuropsychology, 24(4), 343-372. http://doi.org/10.1080/02643290701290146

Crawford, J. R., \& Garthwaite, P. H. (2007b). Using Regression Equations Built From Summary Data in the Neuropsychological Assessment of the Individual Case. Neuropsychology, 21(5), 611-620. http://doi.org/10.1037/0894-4105.21.5.611

Crawford, J. R., \& Howell, D. C. (1998). Comparing an individual's test score against norms derived from small samples. Clinical Neuropsychologist, 12(4), 482-486. http://doi.org/10.1076/clin.12.4.482.7241 
D’Angelo, M. C., Kacollja, A., Rabin, J. S., Rosenbaum, R. S., \& Ryan, J. D. (2015). Unitization supports lasting performance and generalization on a relational memory task: Evidence from a previously undocumented developmental amnesic case. Neuropsychologia, 77 , 185-200. http://doi.org/10.1016/j.neuropsychologia.2015.07.025

D’Angelo, M. C., Rosenbaum, R. S., \& Ryan, J. D. (2016). Impaired inference in a case of developmental amnesia. Hippocampus, 26(10), 1291-1302. http://doi.org/10.1002/hipo.22606

de Flores, R., La Joie, R., Landeau, B., Perrotin, A., Mézenge, F., de La Sayette, V., Chételat, G. (2015). Effects of age and Alzheimer's disease on hippocampal subfields: Comparison between manual and freesurfer volumetry. Human Brain Mapping, 36(2), 463-474. http://doi.org/10.1002/hbm.22640

Duvernoy, H. M. (2005). The human hippocampus (3rd ed.). Berlin-Heidelberg: SpringerVerlag.

Dzieciol, A. M., Bachevalier, J., Saleem, K. S., Gadian, D. G., Saunders, R., Chong, W. K. K., ... Vargha-Khadem, F. (2017). Hippocampal and diencephalic pathology in developmental amnesia. Cortex. http://doi.org/10.1016/j.cortex.2016.09.016

Gadian, D. G., Aicardi, J., Watkins, K. E., Porter, D. A., Mishkin, M., \& Vargha-Khadem, F. (2000). Developmental amnesia associated with early hypoxic-ischaemic injury. Brain, 123 (3), 499-507. http://doi.org/10.1093/brain/123.3.499

Gardiner, J. M., Brandt, K. R., Baddeley, A. D., Vargha-Khadem, F., \& Mishkin, M. (2008). Charting the acquisition of semantic knowledge in a case of developmental amnesia. Neuropsychologia, 46(11), 2865-2868. http://doi.org/10.1016/j.neuropsychologia.2008.05.021

Gardiner, J. M., Brandt, K. R., Vargha-Khadem, F., Baddeley, A., \& Mishkin, M. (2006). Effects of level of processing but not of task enactment on recognition memory in a case of developmental amnesia. Cognitive Neuropsychology, 23(6), 930-948. http://doi.org/10.1080/02643290600588442

Gogtay, N., Giedd, J. N., Lusk, L., Hayashi, K. M., Greenstein, D., Catherine, A., ... Rapoport, J. L. (2007). Dynamic mapping of human cortical development during childhood through early adulthood. Proc Natl Acad Sci $U$ S A, 101(21). 
http://doi.org/10.1073/pnas.0402680101

Guido, G. (2017). The Differential contributions of conceptual representation format and language structure to levels of semantic abstraction capacity. Neuropsychology Review. http://doi.org/10.1007/s11065-016-9339-8

Guillery-Girard, B., Martins, S., Parisot-Carbuccia, D., \& Eustache, F. (2004). Semantic acquisition in childhood amnesic syndrome: a prospective study. Neuroreport, 15(2), 377-381. http://doi.org/10.1097/00001756-200402090-00033

Harding, A. J., Halliday, G. M., \& Kril, J. J. (1998). Variation in hippocampal neuron number with age and brain volume. Cerebral Cortex, 8, 710-718. http://doi.org/10.1093/cercor/8.8.710

Herzmann, G., \& Sommer , W. (2010). Effects of previous experience and biographical knowledge on retrieval processes of faces: An ERP investigation of newly learned faces. Brain Research, 1356, 54-72. http://doi.org/10.1016/j.brainres.2010.07.054

Heuer, E., \& Bachevalier, J. (2011). Effects of selective neonatal hippocampal lesions on tests of object and spatial recognition memory in monkeys. Behavioral Neuroscience, 125(2), 137-149. http://doi.org/10.1037/a0022539

Holdstock, J. S., Mayes, A. R., Roberts, N., Cezayirli, E., Isaac, C. L., O’Reilly, R. C., \& Norman, K. A. (2002). Under what conditions is recognition spared relative to recall after selective hippocampal damage in humans? Hippocampus, 12(3), 341-351. http://doi.org/10.1002/hipo.10011

Hurley, N. C., Maguire, E. A., \& Vargha-Khadem, F. (2011). Patient HC with developmental amnesia can construct future scenarios. Neuropsychologia, 49(13), 3620-3628. http://doi.org/10.1016/j.neuropsychologia.2011.09.015

Huttenlocher, P. R. (1990). Morphometric study of human cerebral development. Neuropsychologia, 28(6), 517-527.

Isaacs, E. B., Watkins, K. E., Lucas, A., Mishkin, M., \& Gadian, D. G. (2003). Developmental amnesia and its relationship to degree of hippocampal atrophy. Proc Natl Acad Sci U $S A, 100(22), 28-31$.

Jefferies, E. (2013). The neural basis of semantic cognition: Converging evidence from 
neuropsychology, neuroimaging and TMS. Cortex, 49(3), 611-625. http://doi.org/10.1016/j.cortex.2012.10.008

Kafkas, A., Migo, E. M., Morris, R. G., Kopelman, M. D., Montaldi, D., \& Mayes, A. R. (2017). Material Specificity Drives Medial Temporal Lobe Familiarity But Not Hippocampal Recollection. Hippocampus, 27(2), 194-209. http://doi.org/10.1002/hipo.22683

Kan, I. P., Alexander, M. P., \& Verfaellie, M. (2009). Contribution of prior semantic knowledge to new episodic learning in amnesia. Journal of Cognitive Neuroscience, 21(5), 938-944. http://doi.org/10.1162/jocn.2009.21066

Kapur, N. (2011). The Paradoxical Brain. Cambridge: Cambridge University Press.

Kapur, N., Thompson, P., Kartsounis, L. D., \& Abbott, P. (1999). Retrograde amnesia: Clinical and methodological caveats. Neuropsychologia, 37(1), 27-30. http://doi.org/10.1016/S0028-3932(98)00065-7

Kawasaki, K., Traynelis, S.F., Dingledine, R. (1990). Different responses of CA1 and CA3 regions to hypoxia in rat hippocampal slice. Journal of Neurophysiology, 63(3), 38594.

Kensinger, E. A., Ullman, M. T., \& Corkin, S. (2001). Bilateral medial temporal lobe damage does not affect lexical or grammatical processing: Evidence from amnesic patient H.M. Hippocampus, 11(4), 347-360. http://doi.org/10.1002/hipo.1049

Khundrakpam, B. S., Lewis, J. D., Zhao, L., Chouinard-Decorte, F., \& Evans, A. C. (2016). NeuroImage Brain connectivity in normally developing children and adolescents. NeuroImage, 134, 192-203. http://doi.org/10.1016/j.neuroimage.2016.03.062

Kitchener, E. G., Hodges, J. R., \& McCarthy, R. (1998). Acquisition of post-morbid vocabulary and semantic facts in the absence of episodic memory. Brain, 121(7), 1313-1327. http://doi.org/10.1093/brain/121.7.1313

La Joie, R., Fouquet, M., Mézenge, F., Landeau, B., Villain, N., Mevel, K., ... Chételat, G. (2010). Differential effect of age on hippocampal subfields assessed using a new high-resolution 3T MR sequence. Neurolmage, 53(2), 506-514. http://doi.org/10.1016/j.neuroimage.2010.06.024

La Joie, R., Perrotin, A., de La Sayette, V., Egret, S., Doeuvre, L., Belliard, S., ... Chetelat, G. 
(2013). Clinical hippocampal subfield volumetry in mild cognitive impairment, Alzheimer's disease and semantic dementia. NeuroImage: Clinical, 3, 155-162. http://doi.org/10.1016/j.nicl.2013.08.007

Laisney, M., Eustache, F. \& Desgranges, B. (2009). Évaluation de la mémoire sémantique relative aux personnes célèbres-SemPer. Revue de neuropsychologie, volume 1,(2), 175-183. doi:10.3917/rne.012.0175.

Lambon Ralph, M. A. (2014). Neurocognitive insights on conceptual knowledge and its breakdown. Philosophical Transactions of the Royal Society of London. Series B, Biological Sciences, 369, 20120392. http://doi.org/10.1098/rstb.2012.0392

Lavenex, P., Lavenex, P. B., \& Amaral, D. G. (2007). Spatial relational learning persists following neonatal hippocampal lesions in macaque monkeys. Nature Neuroscience, 10(2), 234-239. http://doi.org/10.1038/nn1820

LePort, A. K. R., Mattfeld, A. T., Dickinson-Anson, H., Fallon, J. H., Stark, C. E. L., Kruggel, F., ... McGaugh, J. L. (2012). Behavioral and neuroanatomical investigation of Highly Superior Autobiographical Memory (HSAM). Neurobiology of Learning and Memory, 98(1), 78-92. http://doi.org/10.1016/j.nlm.2012.05.002

Loftus, M., Knight, R. T., \& Amaral, D. G. (2000). An analysis of atrophy in the medial mammillary nucleus following hippocampal and fornix lesions in humans and nonhuman primates. Experimental Neurology, 163(1), 180e190. http://doi.org/ 10.1006/exnr.2000.7361

Manjón, J. V., \& Coupé, P. (2016). volBrain: An online MRI brain volumetry system. Frontiers in Neuroinformatics, 10, 30. http://doi.org/10.3389/fninf.2016.00030

Manns, J. R., Hopkins, R. O., Squire, L. R., \& Diego, S. (2003). Semantic memory and the human hippocampus. Neuron, 38, 127-133.

Martins, S., Guillery-Girard, B., Jambaqué, I., Dulac, O., \& Eustache, F. (2006). How children suffering severe amnesic syndrome acquire new concepts? Neuropsychologia, 44(14), 2792-2805. http://doi.org/10.1016/j.neuropsychologia.2006.05.022

Merck, C., Charnallet, A., Auriacombe, S., Belliard, S., Hahn-Barma, V., Kremin, H.. \& Siegwart, H. (2011). La batterie d'évaluation des connaissances sémantiques du 
GRECO (BECS-GRECO): validation et données normatives. Revue de neuropsychologie, volume 3,(4), 235-255. doi:10.3917/rne.034.0235.

Mishkin, M., Vargha-Khadem, F., \& Gadian, D. G. (1998). Amnesia and the organization of the hippocampal system. Hippocampus, 8(3), 212-216. Retrieved from http://doi.wiley.com/10.1002/(SICI)1098-1063(1998)8:3\%3C212::AIDHIPO4\%3E3.3.CO;2-5

Munoz, M., Chadwick, M., Perez-Hernandez, E., Vargha-Khadem, F., \& Mishkin, M. (2011). Novelty preference in patients with developmental amnesia. Hippocampus, 21, 1268-1276. http://doi.org/10.1002/hipo.20836

Murray, E. A., \& Mishkin, M. (1998). Object recognition and location memory in monkeys with excitotoxic lesions of the amygdala and hippocampus. The Journal of Neuroscience, 18(16), 6568-6582.

New, B. (2006). Lexique 3: Une nouvelle base de données lexicales. Actes de la Conférence Traitement Automatique des Langues Naturelles (TALN 2006), avril 2006, Louvain, Belgique.

New, B., Brysbaert, M., Veronis, J., \& Pallier, C. (2007). The use of film subtitles to estimate word frequencies. Applied Psycholinguistics, 28(4), 661-677. http://doi.org/10.1017/S014271640707035X

O'Kane, G., Kensinger, E. A., \& Corkin, S. (2004). Evidence for semantic learning in profound amnesia: An investigation with patient H.M. Hippocampus, 14(4), 417425. http://doi.org/10.1002/hipo.20005

Olsen, R. K., Palombo, D. J., Rabin, J. S., Levine, B., Ryan, J. D., \& Rosenbaum, R. S. (2013). Volumetric analysis of medial temporal lobe subregions in developmental amnesia using high-resolution magnetic resonance imaging. Hippocampus, 23(10), 855-860. http://doi.org/10.1002/hipo.22153

Parker, E. S., Cahill, L., \& McGaugh, J. L. (2006). A case of unusual autobiographical $\begin{array}{llr}\text { remembering. } & \text { Neurocase, } & \text { 35-49. }\end{array}$ http://doi.org/10.1080/13554790500473680

Phillips, J. P., Montague, E. Q., Aragon, M., Lowe, J. R., Schrader, R. M., Ohls, R. K., \& Caprihan, A. (2011). Prematurity affects cortical maturation in early childhood. 
Pediatric Neurology, 45(4), 213-219. http://doi.org/10.1016/j.pediatrneurol.2011.06.001

Picard, L., Mayor-Dubois, C., Maeder, P., Kalenzaga, S., Abram, M., Duval, C., ... Piolino, P. (2013). Functional independence within the self-memory system: New insights from two cases of developmental amnesia. Cortex, 49(6), 1463-1481. http://doi.org/10.1016/j.cortex.2012.10.003

Querbes, O., Aubry, F., Pariente, J., Lotterie, J. A., Demonet, J. F., Duret, V., ... Alzheimer's Disease Neuroimaging Initiative (2009). Early diagnosis of Alzheimer's disease using cortical thickness: Impact of cognitive reserve. Brain, 132(Pt 8), 2036-2047. http://doi.org/10.1093/brain/awp105

Raven, J. C., Court, J. H., \& Raven, J. (1986). Manual for Raven's progressive matrices and vocabulary scales. Oxford, UK: Oxford Psychologists Press.

Rosenbaum, R. S., Carson, N., Abraham, N., Bowles, B., Kwan, D., Köhler, S., ... Richards, B. (2011). Impaired event memory and recollection in a case of developmental amnesia. Neurocase, 17(5), 394-409. http://doi.org/10.1080/13554794.2010.532138

Rosenbaum, R. S., Gao, F., Honjo, K., Raybaud, C., Olsen, R. K., Palombo, D. J., ... Black, S. E. (2014). Congenital absence of the mammillary bodies: A novel finding in a wellstudied case of developmental amnesia. Neuropsychologia, 65, 82-87. http://doi.org/10.1016/j.neuropsychologia.2014.09.047

Rossion, B. (2008). Picture-plane inversion leads to qualitative changes of face $\begin{array}{llll}\text { perception. } & \text { Acta } & \text { 274-289 }\end{array}$ http://doi.org/10.1016/j.actpsy.2008.02.003

Sauvage, M. M., Beer, Z., \& Eichenbaum, H. (2010). Recognition memory: Adding a response deadline eliminates recollection but spares familiarity. Learning and Memory, 17(2), 104-108. http://doi.org/10.1101/lm.1647710

Schmolck, H., Kensinger, E. A., Corkin, S., \& Squire, L. R. (2002). Semantic knowledge in patient H.M. and other patients with bilateral medial and lateral temporal lobe lesions. Hippocampus, 12(4), 520-533. http://doi.org/10.1002/hipo.10039

Sharon, T., Moscovitch, M., \& Gilboa, A. (2011). Rapid neocortical acquisition of long- 
term arbitrary associations independent of the hippocampus. Proceedings of the National Academy of Sciences, 108(3), 1146-1151. http://doi.org/10.1073/pnas.1005238108

Shaw, P., Kabani, N. J., Lerch, J. P., Eckstrand, K., Lenroot, R., Gogtay, N., ... Wise, S. P. (2008). Neurodevelopmental trajectories of the human cerebral cortex. Journal of Neuroscience, 28(14), 3586-3594. http://doi.org/10.1523/JNEUROSCI.530907.2008

Signoret, J.L. Batterie d'efficience mnésique. BEM 144. Paris: Elsevier, 1991.

Smith, C. N., Jeneson, A., Frascino, J. C., Kirwan, B. C., Hopkins, R. O., \& Squire, L. R. (2014). When recognition memory is independent of hippocampal function. Proceedings of the National Academy of Sciences of the United States of America, 111(27), 99359940. http://doi.org/10.1073/pnas.1409878111

Snodgrass, J. G., \& Corwin, J. (1988). Pragmatics of measuring recognition memory: Applications to dementia and amnesia. Journal of Experimental Psychology. General, 117(1), 34-50. http://doi.org/10.1037/0096-3445.117.1.34

Squire, L. R., \& Zola, S. M. (1998). Episodic memory, semantic memory, and amnesia. Hippocampus, 8, 205-211.

Stark, C., Stark, S., \& Gordon, B. (2005). New semantic learning and generalization in a patient with amnesia. Neuropsychology, 19(2), 139-151. http://doi.org/10.1037/0894-4105.19.2.139

Strauss, E., Sherman, E. \& Spreen, O. (2006). A compendium of neuropsychological tests : administration, norms, and commentary. Oxford New York: Oxford University Press

Taylor, K. J., Henson, R. N. A., \& Graham, K. S. (2007). Recognition memory for faces and scenes in amnesia: Dissociable roles of medial temporal lobe structures. Neuropsychologia, $\quad 45(11), \quad 2428-2438$. http://doi.org/10.1016/j.neuropsychologia.2007.04.004

Thomas-Antérion, C., Borg, C., Truche, A., Sciessere, K., Teissèdre, M., \& Bedoin, N. (2009). Expertise de la mémoire sémantique après une lésion cérébrale: le QMN. Lettre de Medecine Physique et de Readaptation, 25(2), 99-100. http://doi.org/10.1007/s11659-009-0139-x 
Thomas-Antérion, C., Puel, M. (2012). La mémoire collective, mémoire des événements publics et des célébrités. Marseille, Solal.

Tulving, E., Hayman, G., \& Macdonald, C. A. (1991). Long-lasting perceptual priming and semantic learning in amnesia: A case experiment. Journal of Experimental Psychology-Learning Memory And Cognition, 17(4), 595-617.

Van der Linden, M., Brédart, S., Depoorter, N., \& Coyette, F. (1996). Semantic memory and amnesia: A case study. Cognitive Neuropsychology, 13(3), 391-413.

Vann, S. D., \& Albasser, M. M. (2009). Hippocampal, retrosplenial, and prefrontal hypoactivity in a model of diencephalic amnesia: Evidence towards an interdependent subcortical-cortical memory network. Hippocampus, 19(11), 10901102. http://doi.org/10.1002/hipo.20574

Vann, S. D., \& Nelson, A. J. D. (2015). The mammillary bodies and memory: More than a hippocampal relay. Progress in Brain Research, 219, 163-185. http://doi.org/10.1016/bs.pbr.2015.03.006

Vargha-Khadem, F., Gadian, D. G., \& Mishkin, M. (2001). Dissociations in cognitive memory: The syndrome of developmental amnesia. Philosophical Transactions of the Royal Society of London. Series B, Biological Sciences, 356(1413), 1435-1440. http://doi.org/10.1098/rstb.2001.0951

Vargha-Khadem, F., Gadian, D., Watkins, K., Connelly, A., Van Paesschen, W., \& Mishkin, M. (1997). Differential effects of early hippocampal pathology on episodic and semantic memory. Science, 277(5324), 376-380. http://doi.org/10.1126/science.277.5324.376

Vargha-Khadem, F., Salmond, C. H., Watkins, K. E., Friston, K. J., Gadian, D. G., \& Mishkin, M. (2003). Developmental amnesia: Effect of age at injury. Proceedings of the National Academy of Sciences of the United States of America, 100(17), 1005510060. Retrieved from http://eprints.ucl.ac.uk/3815/

Verfaellie, M., Koseff, P., \& Alexander, M. P. (2000). Acquisition of novel semantic information in amnesia: Effects of lesion location. Neuropsychologia, 38(4), 484492. http://doi.org/10.1016/S0028-3932(99)00089-5

Vicari, S., Menghini, D., Di Paola, M., Serra, L., Donfrancesco, A., Fidani, P., ... Carlesimo, G. 
A. (2007). Acquired amnesia in childhood: A single case study. Neuropsychologia, 45(4), 704-715. http://doi.org/10.1016/j.neuropsychologia.2006.08.004

Violon A, Wijns C. Le test de la Ruche. Test de perception et d'apprentissage progressif en mémoire visuelle. Braine le Château, Belgique : L'application des techniques modernes, 2004

Warrington, E. K. (1984). The recognition memory test. Windsor, UK: NFER-Nelson.

Wechsler, D. MEM-III. Echelle clinique de mémoire de Wechsler. Troisième éd. Paris: Les Editions du Centre de Psychologie Appliquée, 2001.

Westmacott, R., \& Moscovitch, M. (2001). Names and words without meaning: Incidental postmorbid semantic learning in a person with extensive bilateral medial temporal damage. Neuropsychology, 15(4), 586-596. http://doi.org/10.1037/08944105.15.4.586

Wolk, D. A., Signoff, E. D., \& Dekosky, S. T. (2008). Recollection and familiarity in amnestic mild cognitive impairment: A global decline in recognition memory. Neuropsychologia, $46(7)$,

1965-1978. http://doi.org/10.1016/j.neuropsychologia.2008.01.017

Yonelinas, A. P. (2002). The nature of recollection and familiarity: A review of 30 years of research. Journal of Memory and Language, 46(3), 441-517. http://doi.org/10.1006/jmla.2002.2864

Zola, S. M., \& Squire, L. R. (2001). Relationship between magnitude of damage to the hippocampus and impaired recognition memory. Hippocampus, 11, 92-98.

Zubiaurre-Elorza, L., Soria-Pastor, S., Junque, C., Sala-Llonch, R., Segarra, D., Bargallo, N., \& Macaya, A. (2012). Cortical thickness and behavior abnormalities in children born preterm. PLoS ONE, 7(7), 1-10. http://doi.org/10.1371/journal.pone.0042148 
Ranks

French National Adult Reading Test

$\begin{array}{rcr}\text { Raw score, } \max =40 & 21 & \\ \text { Estimated Full Scale IQ (mean=100, SD }=15) & 100 & 50 \\ \text { Estimated Verbal IQ (mean=100, SD }=15) & 100 & 50 \\ \text { Estimated Performance IQ (mean=100, SD }=15) & 101 & \end{array}$

Intelligence / Wechsler Adult Intelligence Scale, III

$\begin{array}{rcr}\text { Vocabulary } & 36 & 50 \\ \text { Information } & 22 & 75 \\ \text { Comprehension } & 20 & 37 \\ \text { Similarities } & 23 & 63 \\ \text { Digit Span } & 13 & 16 \\ \text { Aetter Number Sequencing } & 8 & 97 \\ \text { Arithmetic } & 13 & 63 \\ \text { Picture Completion } & 22 & 16 \\ \text { Digit Symbol - Coding } & 62 & 63 \\ \text { Block design } & 29 & 25 \\ \text { Matrix reasoning } & 22 & 63 \\ \text { Symbol search } & 29 & \end{array}$

Standard scores, mean $=100, S D=15$

$\begin{array}{rcc}\text { Verbal Comprehension } & 105 & 63 \\ \text { Perceptual Organization } & 93 & 32 \\ \text { Working Memory } & 84 & 14 \\ \text { Processing Speed } & 84 & 14\end{array}$

Memory / Wechsler Memory Scale III 
List of subtests - raw scores

\begin{tabular}{|c|c|}
\hline Information and orientation & 14 \\
\hline Logical Memory I & 11 \\
\hline Face Recognition & 36 \\
\hline Verbal Paired Associates I & 4 \\
\hline Family Pictures I & 8 \\
\hline Words List, 1st recall & 9 \\
\hline Words List, Total recall & 23 \\
\hline Letter Number Sequencing & 8 \\
\hline Spatial Memory & 12 \\
\hline Mental Control & 35 \\
\hline Digit Span & 13 \\
\hline Logical Memory II & 1 \\
\hline Logical Memory II, retention (\%) & 12.5 \\
\hline Face Recognition II & 39 \\
\hline Verbal Paired Associates II & 0 \\
\hline Family Pictures II & 9 \\
\hline Words List II & 0 \\
\hline
\end{tabular}

Standard scores, mean $=100, S D=15$

$\begin{array}{rcc}\text { Verbal Immediate Recall } & 58 & 0.3 \\ \text { Verbal Delayed Recall } & 54 & 0.1 \\ \text { Visual Immediate Recall } & 67 & 1 \\ \text { Visual Delayed Recall } & 75 & 5 \\ \text { Delayed Recognition } & 56 & 0.2 \\ \text { Working Memory } & 77 & 6\end{array}$

Attention \& Executive Functions

2 \& 7 Ruff Selective Attention Test 


$\begin{array}{rrr}\text { Speed } & 267 & 45 \\ \text { Efficiency } & 1.166 & 57\end{array}$

Verbal fluency

$\begin{array}{rcc}\text { Letter } P & 20 & 46 \\ \text { Letter } \mathrm{R} & 20 & 59 \\ \text { Fruits category } & 16 & 35\end{array}$

Ruff Figural Fluency Test

Unique designs (raw score corrected for age \& education)

Trail Making Test

$\begin{array}{lll}\text { Part A (seconds) } & 33 & 72 \\ \text { Part B (seconds) } & 72 & 80\end{array}$

Hayling Test

$\begin{array}{lcc}\text { Part A, total response time (seconds) } & 8427 & 31 \\ \text { Part B, total response time (seconds) } & 8130 & - \\ & & 80\end{array}$

Dual task interference paradigm

Mu index $\quad 92.02 \quad 50$

Table 1. Neuropsychological background 


\section{KA Aged Jon Aged HC Aged}

27

19

22

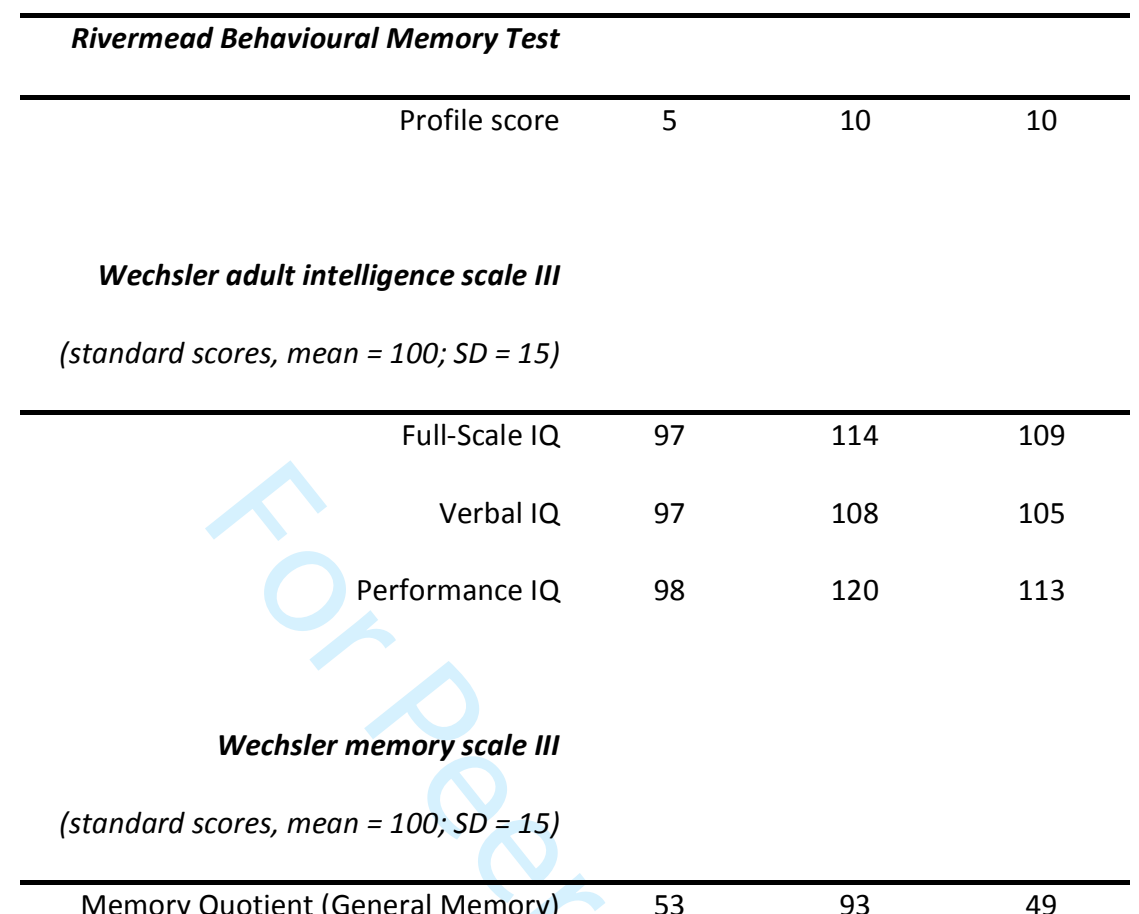

Table 2. Overall memory \& intelligence scores in patient KA vs. patients Jon and HC 
Recall Tests

Raw

scores

\begin{tabular}{|c|c|c|c|}
\hline \multicolumn{4}{|l|}{ Immediate, verbal } \\
\hline Words List I, 1st recall (WMS, 3rd Ed.) & 5 & 42 & 9 \\
\hline Words List I, Total recall (WMS, 3rd Ed.) & 23 & 48 & 0.4 \\
\hline Logical Memory I, total recall (WMS, 4th Ed.) & 18 & 36 & 16 \\
\hline Verbal Paired Associates I, total recall (WMS, 4th Ed.) & 1 & 2 & 0.1 \\
\hline Selective Reminding Test, Mean Recall across 10 trials & 5 & 33 & 0.1 \\
\hline Selective Reminding Test, Consistent Recall & 18 & 35 & 0.1 \\
\hline California Verbal Learning Test, 1st Recall & 2 & 13 & 0.1 \\
\hline California Verbal Learning Test, Total Recall List A & 18 & 23 & 0.1 \\
\hline California Verbal Learning Test, Recall List B & 3 & 19 & 3 \\
\hline \multicolumn{4}{|l|}{ Immediate, visual } \\
\hline Family Pictures I, Recall (WMS, 3rd Ed.) & 8 & 13 & 0.1 \\
\hline Visual Reproduction I, Recall (WMS, 4th Ed.) & 38 & 88 & 50 \\
\hline Visual Paired Associates I, 1st Recall (WMS, Revised Ed.) & 1 & 17 & \\
\hline Visual Paired Associates I, Total Recall (WMS, Revised Ed.) & 6 & 33 & 0.6 \\
\hline Rey Osterreith Complex Figure, Recall & 7 & 19 & 0.1 \\
\hline "La Ruche, spatial localization learning test", 1st Recall & 2 & 20 & 7.5 \\
\hline "La Ruche, spatial localization learning test", Total Recall & 9 & 18 & 0.1 \\
\hline
\end{tabular}

Delayed, verbal

\begin{tabular}{|c|c|c|c|}
\hline Words List II, Delayed recall (WMS, 3rd Ed.) & 0 & 0 & 0.1 \\
\hline Logical Memory II, Delayed recall (WMS, 4th Ed.) & 1 & 2 & 0.1 \\
\hline Verbal Paired Associates II, Delayed recall (WMS, 4th Ed.) & 0 & 0 & 0.1 \\
\hline Selective Reminding Test, Delayed recall & 0 & 0 & 0.1 \\
\hline fornia Verbal Learning Test, Post interference Free Recall & 0 & 0 & 0.1 \\
\hline
\end{tabular}




$\begin{array}{rlcr}\text { California Verbal Learning Test, Post interference Cued Recall } & 1 & 6 & 0.1 \\ \begin{array}{r}\text { California Verbal Learning Test, Delayed Free Recall } \\ \text { California Verbal Learning Test, Cued Recall }\end{array} & 0 & 0 & 0 \\ \text { Double Memory Test, Delayed cued recall } & 10 & 21 & 0.1\end{array}$

Delayed, visual

\begin{tabular}{|c|c|c|c|}
\hline Family Pictures II, Delayed recall (WMS, 3rd Ed.) & 9 & 14 & 0.4 \\
\hline Visual Reproduction II, Delayed Recall (WMS, 4th Ed.) & 0 & 0 & 0.1 \\
\hline Visual Paired Associates II, Delayed recall (WMS, Revised Ed.) & 2 & 33 & 0.1 \\
\hline Rey Osterreith Complex Figure, Delayed recall & 1.5 & 4 & 0.1 \\
\hline "La Ruche, spatial localization learning test", Delayed Recall & 1 & 10 & 0.1 \\
\hline
\end{tabular}

Table 3. Recall memory performances of patient KA. "La Ruche" test was taken from Violon \& Wijns (1984) 


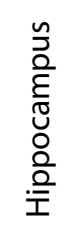

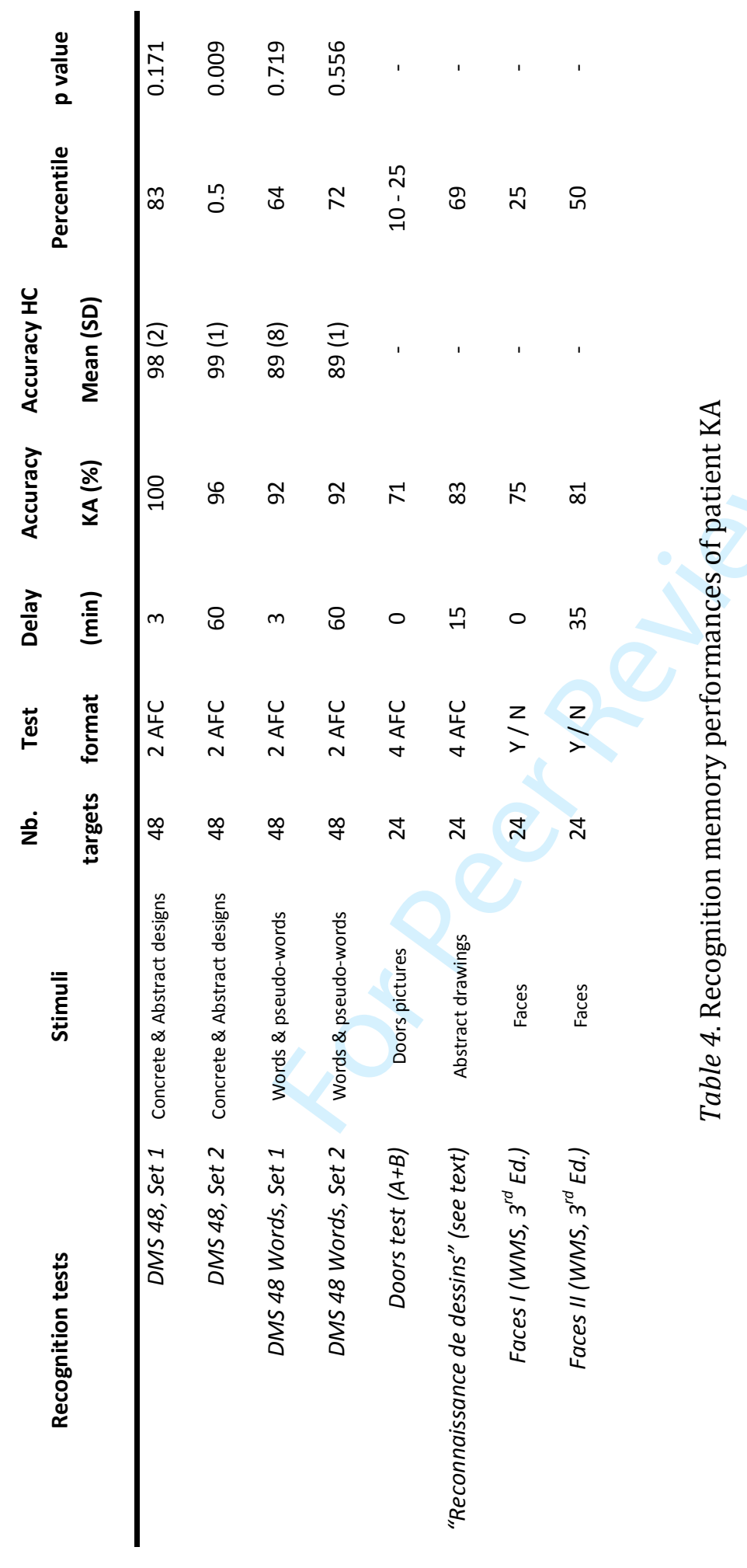

8

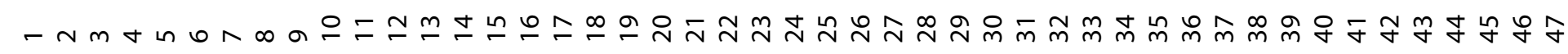




$\begin{array}{ccc}\text { Patient KA } & \text { Patient KA } & \text { Healthy Controls } \\ \text { raw volumes } & \text { Normalized } & \text { Normalized volumes } \\ \text { (cm3) } & \text { volumes (\%) } & (95 \% \mathrm{IC})\end{array}$

\begin{tabular}{rrrr}
\hline \multicolumn{1}{l}{ Segmented structures } \\
\hline Tissue segmentation & & & \\
\hline White Matter & $478.62^{*}$ & 32.26 & {$[32.95-45.17]$} \\
Grey Matter & 782.89 & 52.76 & {$[44.17-55.44]$} \\
Cerebro Spinal Fluid & 222.26 & 14.98 & {$[5.83-16.44]$}
\end{tabular}

Subcortical structures

\begin{tabular}{rccc}
\hline Lateral Ventricles & $48.24^{*}$ & 3.25 & {$[0.00-1.97]$} \\
Putamen & 7.72 & 0.52 & {$[0.50-0.71]$} \\
Thalamus & $9.77^{*}$ & 0.66 & {$[0.73-0.93]$} \\
Globus pallidus & 2.02 & 0.14 & {$[0.14-0.21]$} \\
Hippocampus & $3.30^{*}$ & 0.22 & {$[0.46-0.64]$} \\
Amygdala & 1.63 & 0.11 & {$[0.09-0.15]$} \\
Accumbens & $0.48^{*}$ & 0.03 & {$[0.03-0.07]$}
\end{tabular}

Table 5. Results of automated MRI brain volumetry in Patient KA (VolBrain system, Manjón \& Coupé, 2016). ${ }^{*}=\mathrm{p}<.05$ 


\section{Controls}

KA's

Stimuli

Mean (SD)/ Percentile p value

cut-off

\section{Raw scores}

\begin{tabular}{|c|c|c|c|c|c|}
\hline Standardized tasks & & & & & \\
\hline \multicolumn{6}{|l|}{ BECS-Greco battery } \\
\hline Words matching test, $\max =40$ & Words (objects) & 40 & Cut-off $=38$ & - & - \\
\hline Pictures matching test, $\max =40$ & Drawings (objects) & 40 & Cut-off $=38$ & - & - \\
\hline Identity matching test, $\max =20$ & Drawings (objects) & 19 & Cut-off=19 & - & - \\
\hline Pictures naming, $\max =40$ & Drawings (objects) & 39 & Cut-off $=38$ & - & - \\
\hline Questionnaire, $\max =240$ & Words (objects) & 235 & Cut-off $=233$ & - & - \\
\hline \multicolumn{6}{|l|}{ Mill Hill Vocabulary scale } \\
\hline Part B & Words (concepts) & 32 & & $75-90$ & - \\
\hline \multicolumn{6}{|l|}{ EVE 30 battery } \\
\hline Evocation, $\max =60$ & Famous events & 48 & & 99 & - \\
\hline Multiple-choice recognition, $\max =30$ & Famous events & 29 & & 91 & - \\
\hline Details, $\max =60$ & Famous events & 39 & & 95 & - \\
\hline Datation, $\max =30$ & Famous events & 20 & & 95 & - \\
\hline \multicolumn{6}{|l|}{ TOP 30 battery } \\
\hline Evocation, $\max =60$ & Famous faces & 55 & & 96 & - \\
\hline Multiple-choice recognition, $\max =30$ & Famous faces & 28 & & 37 & - \\
\hline Details, $\max =60$ & Famous faces & 50 & & 93 & - \\
\hline Experimental tasks & & & & & \\
\hline
\end{tabular}

\section{Famous buildings task}

Familiarity decision, $\max =16$

Famous buildings pictures 


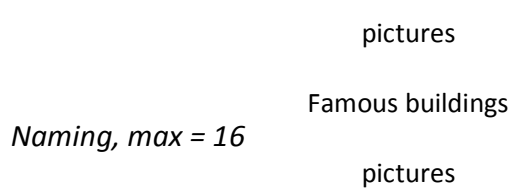

SEMPer battery

$\begin{aligned} \text { Familiarity decision for names, } \max & =32 \\ \text { Names matching, Part A, } \max & =16 \\ \text { Names matching, Part } B, \max & =16 \\ \text { Familiarity decision for faces, } \max & =32 \\ \text { Faces matching, Part A, } \max & =16 \\ \text { Faces matching, Part } B, \max & =16 \\ \text { Naming, } \max & =32\end{aligned}$

\section{Famous names}

Famous names

Famous names

Famous faces

Famous faces

Famous faces

Famous faces

\section{Recent Concepts Questionnaire}

\section{6-1997 period}

Free recall (definition), $\max =11$

Multiple Choice Questionnaire, $\max =11$

Real usage forced choice, $\max =11$

\section{Recent Concepts Questionnaire}

\section{6-2007 period}

Free recall (definition), $\max =11$

Words

Words

Words
Words

Words
8

11

11
32

14

$11.3(3.4)$

74

0.529

14

32

16

15

32

Words

10

11

11

$9.4(1.5)$

63

$10.6(0.9)$

$11(0)$
0.275

0.270

0.937

0.329

0.391

0.465

0.231
0.737

0.703

65

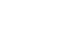

Multiple Choice Questionnaire, $\max =11$

Real usage forced choice, $\max =11$
$9.6(1.7)$

22

$10.6(0.9)$

65

$11(0)$

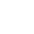

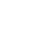




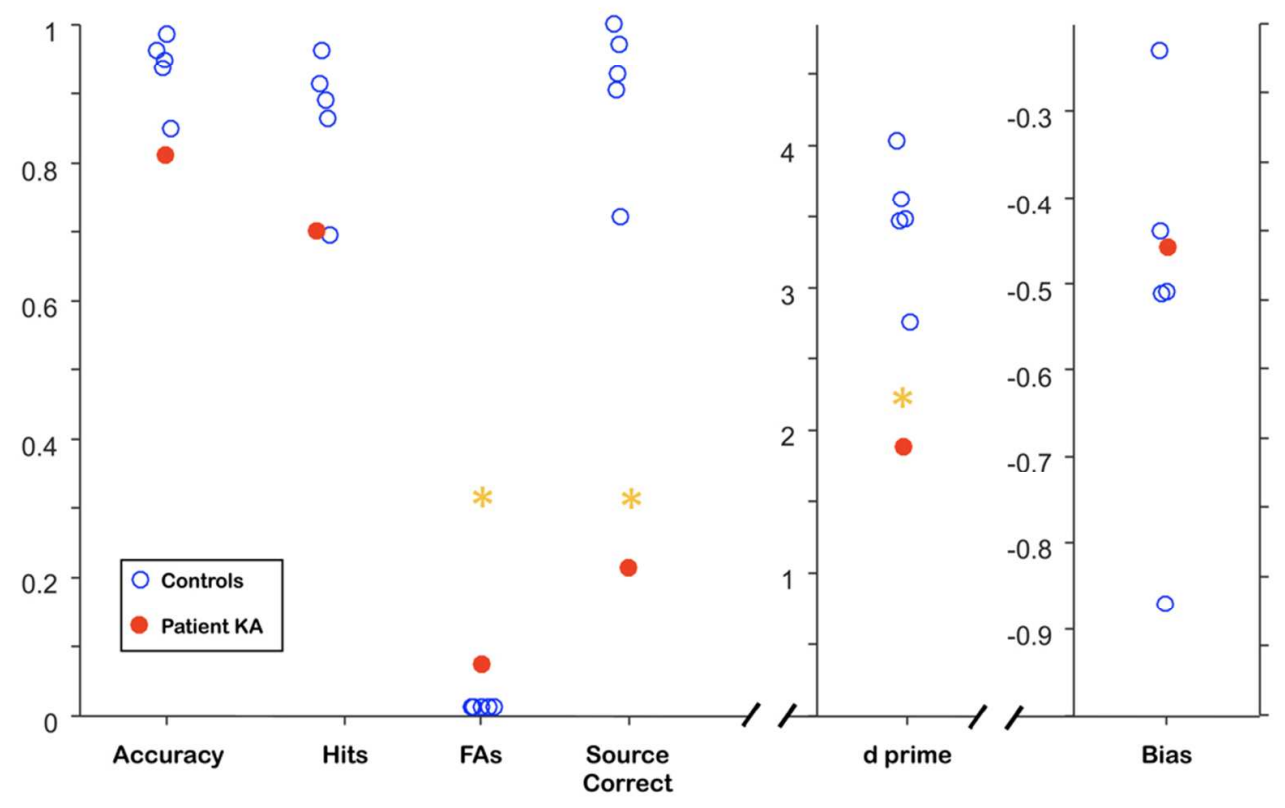

Figure 1. Source Quadrant Location Memory task. Yellow asterisks indicate impaired performances $(p<.05)$.

$$
361 \times 270 \mathrm{~mm}(72 \times 72 \mathrm{DPI})
$$




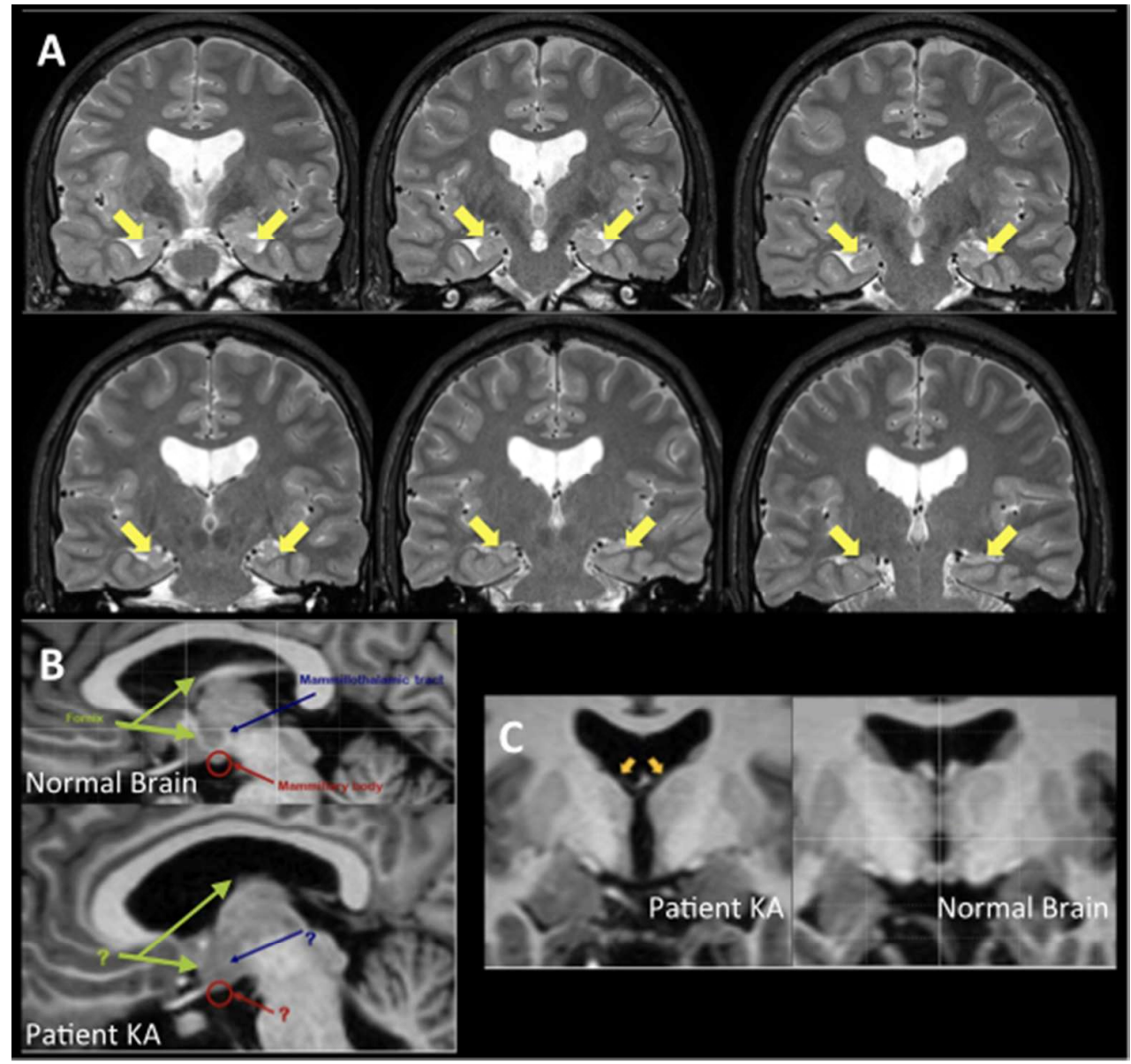

Figure 2. (A) Patient KA's T2-weighted MRI scans. Yellow arrows indicate bilateral hippocampal atrophy; (B) Fornix, mammillary bodies and mammillo-thalamic tract abnormalities in patient KA (bottom) vs a healthy control (top); (C) Anterior thalamic nuclei atrophy in patient KA (left image, yellow arrows) vs a healthy control (right image).

$196 \times 185 \mathrm{~mm}(72 \times 72 \mathrm{DPI})$ 


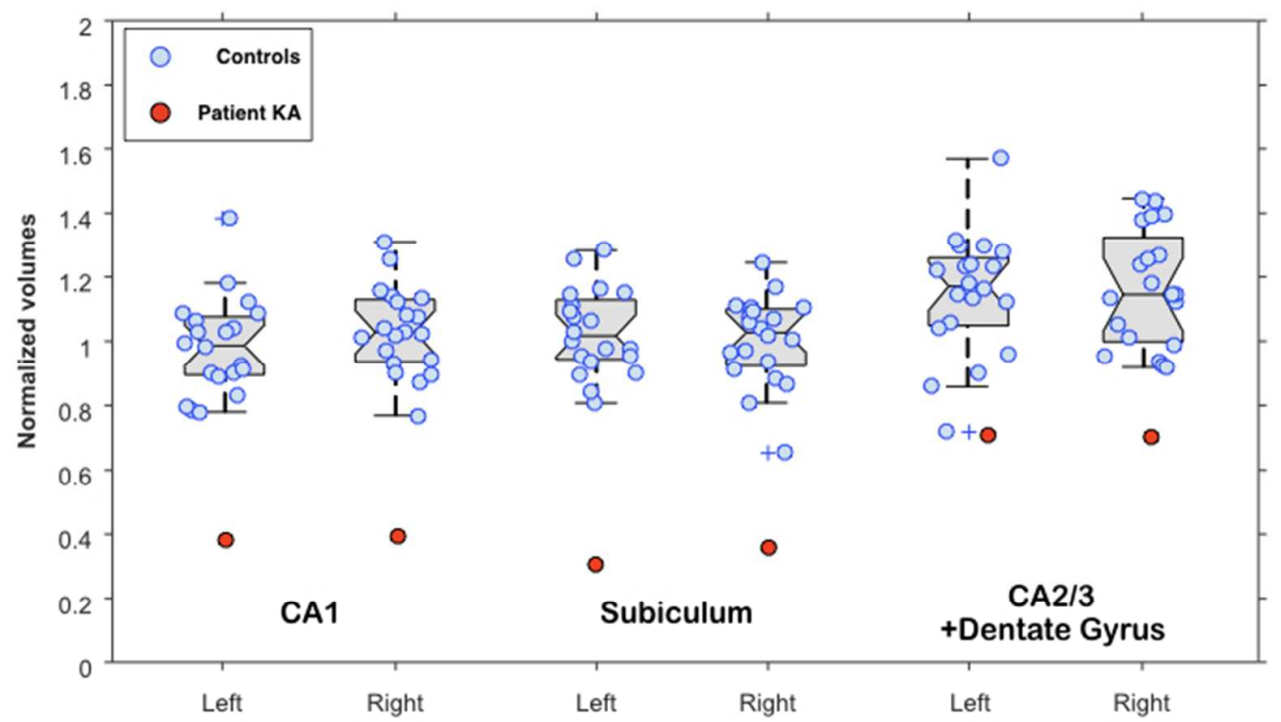

Figure 3. Hippocampal subfields volumetry in patient KA vs 20 healthy controls. (Crawford's modified t-tests, all $p$ values $<0.05$ ).

$238 \times 135 \mathrm{~mm}(72 \times 72 \mathrm{DPI})$ 


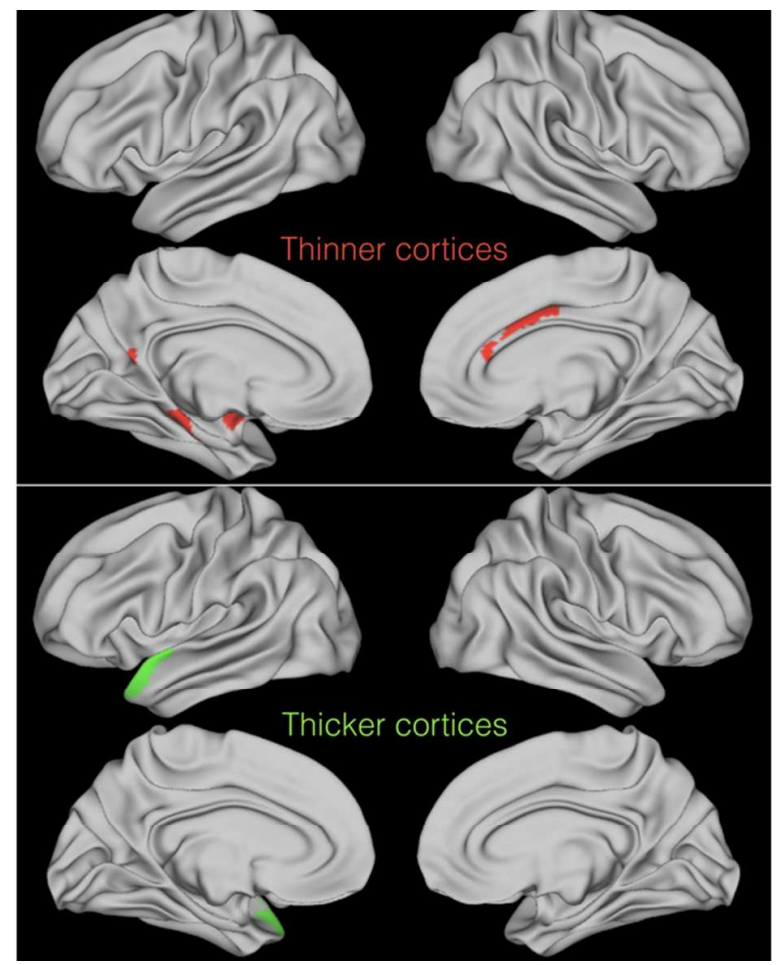

Figure 4. Z-score map for whole-brain cortical thickness estimates in patient KA vs 10 healthy controls. Red indicates abnormally thick cortices, blue indicates abnormally thin cortices. Cut-off set at 1.65 standard deviation of the mean. See text for detailed results.

$361 \times 270 \mathrm{~mm}(72 \times 72 \mathrm{DPI})$ 

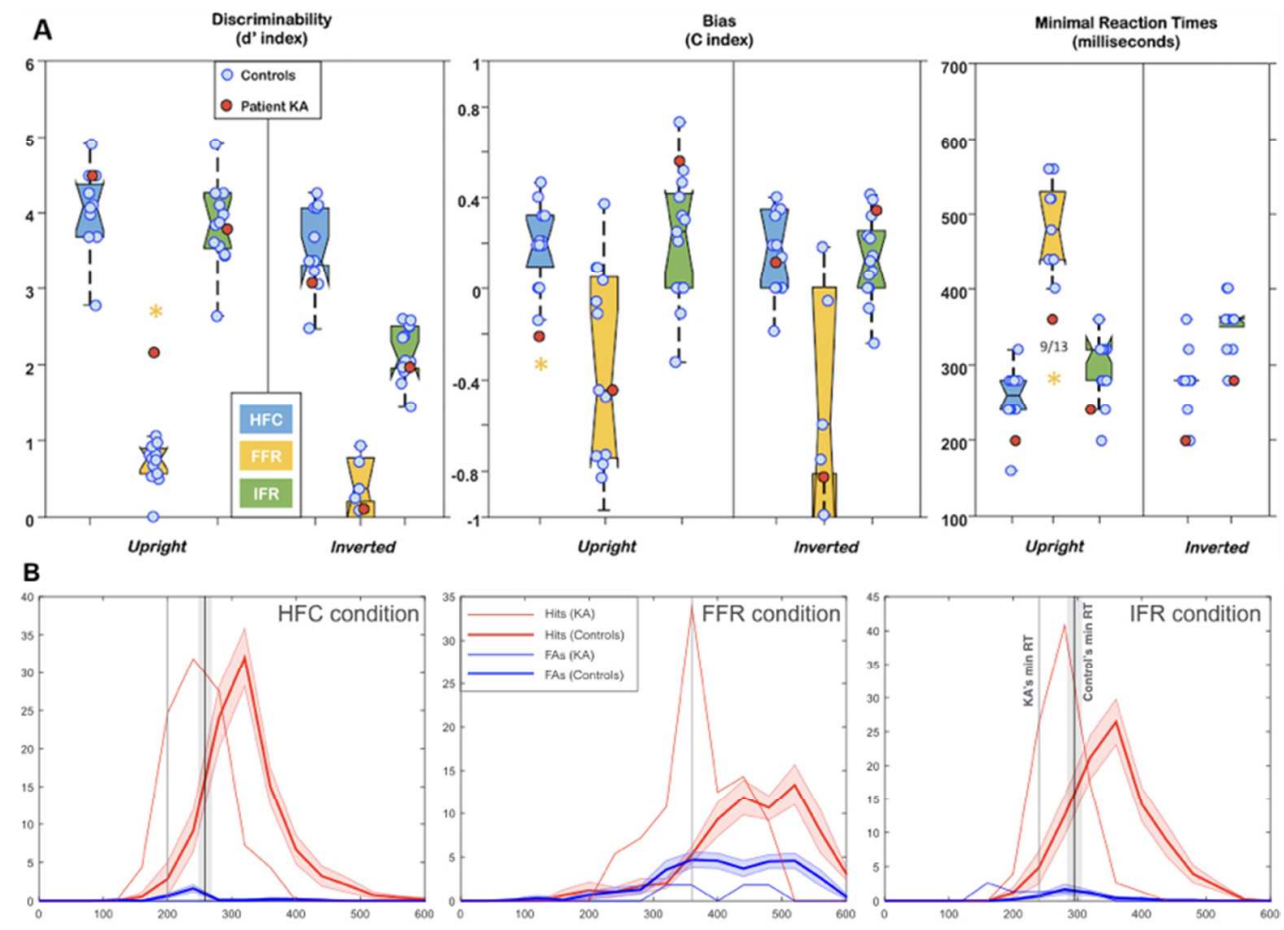

Figure 5. (A) Patient KA's performances during experiments 1 (Human Face Categorization [HFC], blue boxplots), 2 (Famous Faces Recognition [FFR], yellow boxplots), and 3 (Individual Faces Recognition [IFR], green boxplots). Yellow asterisks indicate $\mathrm{p}<0.05$. [HFC = Human Face Categorization, experiment 1; FFR = Famous Faces Recognition, experiment 2; IFR = Individual Face Recognition, experiment 3]; (B) Reaction times distributions for each task (Upright conditions only), where $Y$ axis shows \% responses and $X$ axis time bins. Dashed areas represent standard error of the mean. 
A

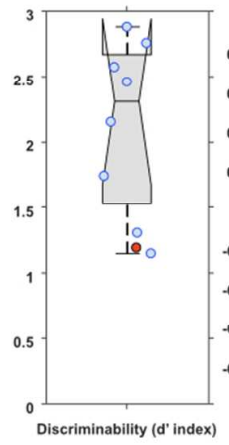

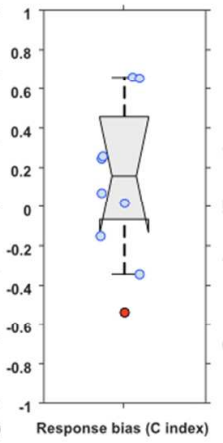

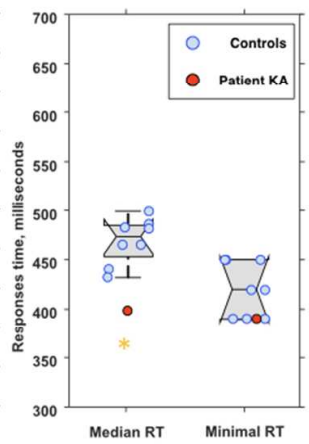

\section{B}

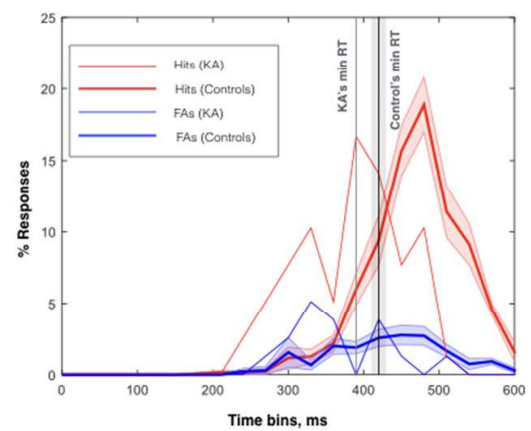

Figure 6. Context-free learning experiment. (A) Learning performances of patient KA (red circle) and controls (blue circles) assessed through discriminability ( $d^{\prime}$ index, left plot), response bias ( $C$ index, middle plot) and response times (Median response time and Minimal reaction time, right plot). Yellow asterisk indicate $p<0.05$. (B) Reaction times distributions, where $Y$ axis shows \% responses and $X$ axis time bins. Dashed areas represent standard error of the mean. 